\title{
Curcumin Loaded in Niosomal Nanoparticles Improved the Anti-tumor Effects of Free Curcumin on Glioblastoma Stem-like Cells: an In Vitro Study
}

\author{
Sajad Sahab-Negah ${ }^{1,2,3}$ - Fatemeh Ariakia ${ }^{1,2}$ - Mohammad Jalili-Nik ${ }^{4,5}$ • Amir R. Afshari ${ }^{6,7} \cdot$ Sahar Salehi $^{8,9}$. \\ Fariborz Samini $^{10} \cdot$ Ghadir Rajabzadeh $^{8} \cdot$ Ali Gorji $^{1,2,3,11,12}$ (D)
}

Received: 9 December 2019 / Accepted: 22 April 2020 / Published online: 19 May 2020

(C) The Author(s) 2020

\begin{abstract}
Using a novel curcumin-loaded niosome nanoparticle (CM-NP), the present study was designed to evaluate the effect of curcumin on human glioblastoma stem-like cells (GSCs). CM-NP has a diameter of $\sim 60 \mathrm{~nm}$ and a zeta potential of $\sim-$ $35 \mathrm{mV}$ with a constant physicochemical stability. The cytotoxic effects of free curcumin (CM) and CM-NP were investigated on GSCs obtained during the removal of a brain tumor. Both CM and CM-NP caused a dose-dependent decrease in cell proliferation and viability of GSCs. The IC50 values of CM and CM-NP on GSCs were 50 and $137 \mu \mathrm{g} / \mathrm{ml}$ after $24 \mathrm{~h}$, respectively. CM-NP exerted significantly higher effects on GSC viability, apoptosis, cell cycle arrest, and the expression of Bax, a proapoptotic marker, compared with CM. In addition, the migration of GSCs was significantly impaired following the administration of CM-NP compared with CM. Furthermore, CM-NP significantly increased the values of reactive oxygen species and decreased the mRNA expressions of NF- $\mathrm{KB}$ and IL-6 of GSCs compared with CM. Our data also revealed that CM-NP could significantly reduce the invasiveness of GSCs compared with CM, possibly via MCP-1-mediated pathways. In addition, CM-NP exhibited a significantly greater inhibitory effect on colony formation of GSCs compared with CM. These data indicate that CMNP exhibited stronger anti-tumor effects on GSCs than CM. Although further in vivo investigations are warranted, our results suggest that CM-NP could be an ideal carrier to deliver curcumin for potential therapeutic approaches into glioblastoma.
\end{abstract}

Keywords Brain tumor $\cdot$ Cytokine $\cdot$ Cellular engineering $\cdot$ Cell death $\cdot$ Glioma

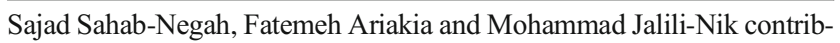
uted equally to this work.

Ghadir Rajabzadeh

Gh.Rajabzadeh@rifast.ac.ir

$\triangle$ Ali Gorji

gorjial@uni-muenster.de

1 Neuroscience Research Center, Mashhad University of Medical Sciences, Mashhad, Iran

2 Department of Neuroscience, Faculty of Medicine, Mashhad University of Medical Sciences, Mashhad, Iran

3 Shefa Neuroscience Research Center, Khatam Alanbia Hospital, Tehran, Iran

4 Student Research Committee, Mashhad University of Medical Sciences, Mashhad, Iran

5 Department of Medical Biochemistry, Faculty of Medicine, Mashhad University of Medical Sciences, Mashhad, Iran
6 Department of Pharmacology, Faculty of Medicine, Mashhad University of Medical Sciences, Mashhad, Iran

7 Natural Products and Medicinal Plants Research Center, North Khorasan University of Medical Sciences, Bojnurd, Iran

8 Department of Food Nanotechnology, Research Institute of Food Science and Technology, Mashhad, Iran

9 Department of Materials and Metallurgical Engineering, Materials and Metallurgical Engineering Faculty, Semnan University, Semnan, Iran

10 Department of Neurosurgery, Faculty of Medicine, Mashhad University of Medical Sciences, Mashhad, Iran

11 Department of Neurosurgery and Department of Neurology, Westfälische Wilhelms-Universität, 48149 Münster, Germany

12 Epilepsy Research Center, Westfälische Wilhelms-Universität Münster, 48149 Münster, Germany 


\section{Introduction}

Glioblastoma multiform (GBM) is the most prevalent and lethal malignant primary brain tumor originating from glial cells, representing one-third of the whole central nervous system tumors [1]. Current therapeutic options available for GBM have limited efficacy, offering short-term survival improvement with a considerable side effects. Thus, improvement in available therapeutic approaches and the implementation of novel treatments are warranted. GBM contains functional subsets of tumorigenic and self-renewing stem cells called glioblastoma stem-like cells (GSCs). The characteristic features of GSCs, such as infiltrative property, resistance to various treatments, and progressive nature, strongly suggested their key role in tumor initiation, invasion, and recurrence [2]. GSCs are identified as a novel target for the treatment of resistant tumor cells and prevention of cancer recurrence $[3$, 4].

Curcumin, a natural compound in turmeric, has been traditionally believed to exert desirable therapeutic effects on several chronic neurological diseases $[5,6]$. Both experimental studies and clinical trials point to anti-neoplastic effects of curcumin $[7,8]$. Numerous investigations suggest that curcumin may be used as an adjuvant substance to augment available treatments of GBM $[9,10]$. The chemotherapeutic effects of curcumin on different GBM cell lines indicate implication of a variety of signaling pathways and molecular targets, including (i) induction of autophagy via suppression of the Akt/mammalian target of rapamycin and activation of extracellular signal-regulated kinase pathways [11-13], (ii) inhibition of cell growth, migration, and invasiveness through the modulation of the matrix metalloproteinases (MMP), and inhibition of the Janus kinase (JAK)/signal transducers and activators of transcription (STAT) 3 signaling pathway [14-17], and (iii) modulation of tumor invasion, angiogenesis, and metastasis via upregulation of apoptotic pathways and induction of $\mathrm{G} 2 / \mathrm{M}$ phase arrest as well as inhibition of nuclear factor $\mathrm{kB}(\mathrm{NF}-\mathrm{kB})$ and phosphoinositide 3 kinase $[18,19]$ Furthermore, curcumin inhibits patient-derived GSC viability and proliferation as well as sphere- and colony-forming potentials, possibly via a reactive oxygen species (ROS)-dependent pathway as well as the JAK/STAT3 pathway [20]. However, the therapeutic potential of curcumin is limited due to its rapid metabolism as well as indigent water solubility and absorption [21].

Nanotechnology-based therapeutic delivery systems, including nanoparticles, nano-emulsions, and liposomes, have emerged to promote the bioavailability, low aqueous solubility, cellular uptake, and anti-tumor activity of curcumin [5, 22], which possibly improve targeted delivery and cellular internalization of the curcumin nanoparticle into the tumor cells [6]. Various biodegradable polymers of natural or synthetic origin have been used for curcumin nano-encapsulation
[23-25]. The effects of different nano-sized particles of curcumin have been examined in GBM cells in both in vitro studies and clinical trials [26, 27]. Curcumin nanoparticles have been shown to suppress the growth of multiple GBM cell lines through the reduction of stem-like tumor cells [28, 29]. In an attempt to improve the targeting property for efficient curcumin therapeutic approaches on GBM, we designed a novel curcumin-loaded niosome system to evaluate its effect on GSCs. Niosomes, composed of a combination of a nonionic surfactant and lipid compounds with an overall neutral charge [30,31], are biodegradable, biocompatible, non-immunogenic, and safe for delivery of both hydrophilic and hydrophobic drugs [31]. Niosomes have the ability to overcome the blood-brain barrier (BBB) and raise the stability and concentrations of the encapsulated medication within the brain [32].

The majority of prior studies have focused on the effect of curcumin on GBM cell lines and limited investigations evaluated its effect on GSCs obtained during tumor surgery. In this in vitro study, we assessed whether curcumin-encapsulated noisome nanoparticle (CM-NP) can exert considerably greater water solubility and systemic bioavailability than free curcumin. Furthermore, the effect of CM-NP on proliferation, survival, migration, and invasive properties of GSCs was compared with free curcumin. Finally, the signal transduction pathways mediating CM-NP and free curcumin effects on GSCs were investigated.

\section{Materials and Methods}

\section{Study Design}

Niosome nanoparticles were prepared using the thin-film hydration method. Formation of niosomes requires an amphiphilic molecule composed of two main parts, a hydrophilic head group and a hydrophobic tail. Curcumin was encapsulated in the shell of niosome nanoparticles and the characteristics of CM-NP were assessed. To determine the anti-tumor activity of CM-NP, GSCs were cultured and cultivated with CM-NP. The effects of CM-NP on different properties of GSCs were evaluated (Fig. 1).

\section{Preparation of CM-NP}

Niosome formulation was synthesized using the thin-film hydration method with some modifications, as described previously [33, 34]. Briefly, sorbitan monostearate (Span 60), Tween 60 (1:2 M ratio), cholesterol, and dicetyl phosphate (all obtained from Sigma, Germany) were weighted and dissolved in $10 \mathrm{ml}$ of ethanol-chloroform mixture $(1: 2 v / v)$. The organic solvent was evaporated in a rotary evaporator (Rotavapor® R-114, BUCHI, USA) in order to form a thin film in the round bottom flask at $60{ }^{\circ} \mathrm{C}$. The thin film was 

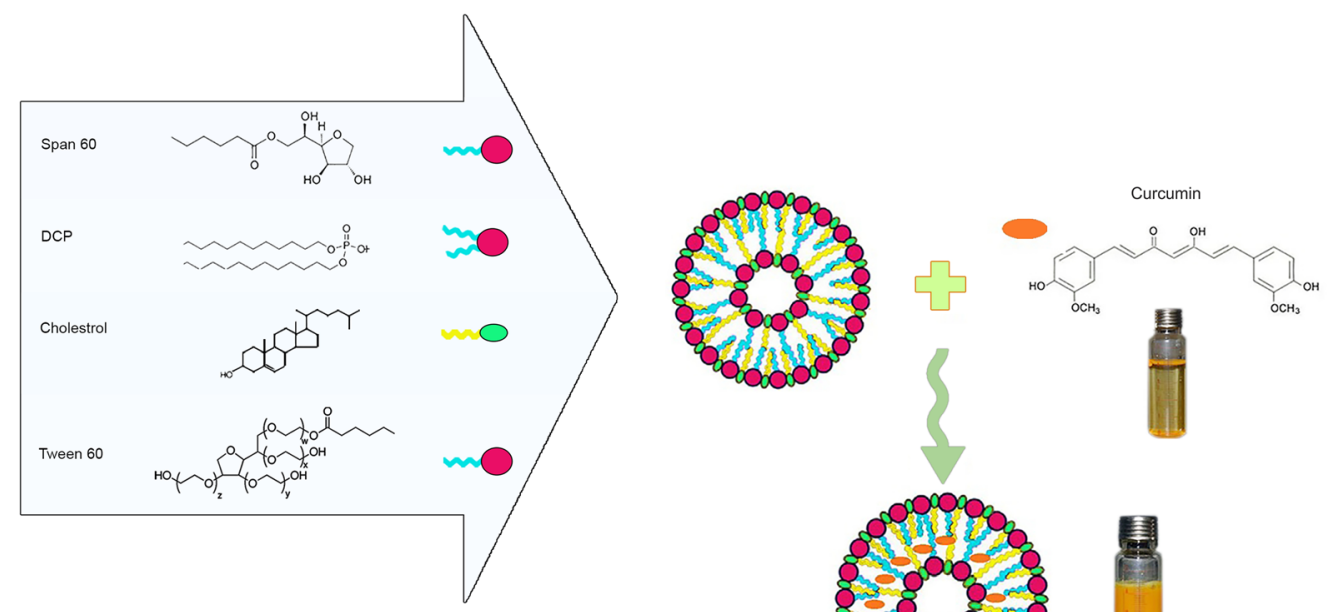

Fig. 1 A schematic overview of synthetic procedure of the nanoniosome-loaded curcumin, its delivery path, and its ability of targeting glioblastoma stem-like cells (GSCs). The niosomal carrier (Tween 60Span 60-cholestrol) enhanced the entrapment efficiency of curcumin and di-acetyl phosphate (DCP) was used for loading curcumin as well as

rehydrated with phosphate-buffered saline (PBS) at $\mathrm{pH}$ 7.4. Subsequently, to obtain a uniform niosome, the hydrated niosome was sonicated using a sonicator (sonopuls HD3200 , Bandelin, Germany) with $90 \%$ amplitude, $150 \mathrm{~W}$ power, and $20 \mathrm{kHz}$ frequency for $5 \mathrm{~min}$ ( $30 \mathrm{~s}$ on and $10 \mathrm{~s}$ off). To encapsulate curcumin, $100 \mu \mathrm{M}$ of curcumin (Sigma, USA) was dissolved in chloroform-ethanol mixture along with niosome. After preparation, samples were stored at $4{ }^{\circ} \mathrm{C}$ for further experiments.

\section{Morphology Analyses}

\section{Size and Zeta Potential Assessments}

The mean size and size distribution of niosomes were assessed using Zeta-sizer Nano ZS (Malvern Instruments Ltd., UK) with a helium-neon laser at $630 \mathrm{~nm}$ in room temperature. Briefly, niosomal samples were appropriately diluted (1:10) with deionized water and the size of the sample was measured based on dynamic light scattering (DLS) method. The zeta potential of niosomes was detected by the abovementioned instrument. The size distribution was measured by the polydispersity index. Niosomal samples were filtered through $0.45-\mu \mathrm{m}$ membrane filters (Satrious, Germany) to avoid multiple scattering. The real refractive and the imaginary refractive indices were set at 1.33 and 0.01 , respectively.

\section{Transmission Electron Microscopy (TEM)}

To analyze the effective formation of the vesicles of nanoparticles, TEM was used. The sample was diluted (1:10) with deionized water to decrease the vesicle concentration. A drop of $2 \%$ uranyl acetate was immediately added to the diluted sample for $2 \mathrm{~min}$ and sonicated for $1 \mathrm{~min}$ in an ultrasound bath at room temperature. A drop of this solution was located on a copper mesh for $2 \mathrm{~min}$. After another min, the excess solution was removed by a filter paper and the grid surface was air-dried at room temperature. Finally, TEM images of nanoparticles were taken using a Leo 912 OMEGA transmission electron microscope (Germany). 


\section{Determination of Entrapment Efficiency}

Entrapment efficacy (EE) was performed by spectrophotometry. First, different concentrations of curcumin in methanol were applied to set calibration curve. Then, $5 \mathrm{ml}$ niosome suspension was loaded on an Amicon MPS (Millipore, USA) filtration tube and centrifuged at $6000 \mathrm{rpm}$ (Hettich Tuttlingen, Germany). Entrapped niosome remained at the top of the tube membrane and supernatant was separated in the bottom filter cup. The concentration of free curcumin in the supernatant was measured by absorbance measurement at $426 \mathrm{~nm}$. The EE\% was calculated by

$\mathrm{EE} \%=\frac{\text { Total amount of curcumin }- \text { free curcumin }}{\text { Total amount of curcumin }} \times 100$

\section{In Vitro Curcumin Release}

In vitro drug release profile of curcumin-loaded niosome nanoparticles was performed by the direct dispersion method as described before [35]. A known amount of CM-NP $(150 \mu \mathrm{g} / \mathrm{ml})$ was dispersed in $33 \mathrm{ml} \mathrm{PBS}$ at $\mathrm{pH} 7.4$ and was divided equally in 33 microfuge tubes. A thermostable water bath was used to keep the tubes at $37^{\circ} \mathrm{C}$. Free curcumin was insoluble in water; thus, the solution was shaken (100 rpm, $10 \mathrm{~min}$ ) to separate the released curcumin from the loaded nanoparticles at predetermined time intervals $(0,2,4,6,24$, $48,72,84,96,120,132,156,180,204$ h). The released curcumin was re-dissolved in methanol and the absorbance was measured using spectrophotometer at $426 \mathrm{~nm}$ and the values of the released curcumin were measured by a standard curve of curcumin in methanol.

\section{Fourier Transform Infrared Spectroscopy (FTIR)}

To assess the compatibility of curcumin with niosome, a FTIR machine (Thermo Nicolet) was used to determine the unloaded and loaded curcumin in niosome. The samples were then scanned between the range of 4000 and $400 \mathrm{~cm}^{-1}$ with a resolution of $4 \mathrm{~cm}^{-1}$.

\section{Differential Scanning Calorimetry (DSC)}

Calorimetric analyses were performed using a differential scanning calorimetry (Eirsa, Iran). The equipment was calibrated by indium. In all experiments, the reference pan was empty. Firstly, $14 \mathrm{mg}$ of niosome (loaded and unloaded) was transferred from the bulk to the aluminum crucible and calorimetric analysis was done using a heating scan from 5 to $350{ }^{\circ} \mathrm{C}$ at a scan rate of $5{ }^{\circ} \mathrm{C} / \mathrm{min}$ at nitrogen atmosphere. After the calorimetric characterization of each sample, the interaction between components was assessed.

\section{GSC Culture}

The tissue sample was collected during tumor resection from a 55-year-old man who suffered from GBM. Informed consent was obtained from the patient. The experimental protocol was evaluated and approved by the Ethical Committee of Shefa Neuroscience Research Center, Tehran, Iran. The tissue was mechanically dissociated and enzymatically digested to a single-cell suspension. The GSCs were grown in Dulbecco's modified Eagle's medium/F12 medium (Gibco, Germany), $2 \%$ fetal bovine serum (Sigma, Germany), 100 units $/ \mathrm{ml}$ of penicillin-streptomycin (Sigma, Germany), 2\% B27 (Gibco, Germany), $1 \%$ L-glutamine (Sigma, Germany), $1 \%$ N2 (Gibco, Germany), $20 \mathrm{ng} / \mathrm{ml}$ epidermal growth factor (Sigma, Germany), and $20 \mathrm{ng} / \mathrm{ml}$ basic fibroblast growth factor (Sigma, Germany) at $37{ }^{\circ} \mathrm{C}$ in a humidified incubator $(5 \%$ $\mathrm{CO}_{2}$ ). The medium was changed twice a week. Cells between passages 4 and 8 were used for the experiments.

\section{Cell Proliferation Assay}

The cell proliferation was evaluated by MTT assay (Atocel, Austria). GSCs $\left(1 \times 10^{4} /\right.$ well $)$ were seeded in 96-well culture plates and kept overnight. These cells were incubated with curcumin and CM-NP for the next 24 or $48 \mathrm{~h}$. After that, $10 \mu \mathrm{l}$ of the MTT solution in PBS $(5 \mathrm{mg} / \mathrm{ml})$ was added to each well at a final concentration of $0.05 \%$. After $3-4 \mathrm{~h}$, the supernatant was removed and to dissolve the formazan crystals, $100 \mu$ l of dimethyl sulfoxide (Sigma, Germany) was added to each well. Then, the microplates were gently shaken in the dark for $60 \mathrm{~min}$ and the absorbance was assessed between 545 and $630 \mathrm{~nm}$ by a Stat FAX303 plate reader.

\section{Viability Assay}

The viability of GSCs was evaluated using LIVE/DEAD Viability/Cytotoxicity kit (Invitrogen, Molecular Probes, USA). GSCs $\left(2 \times 10^{4}\right.$ per well) were seeded in a 96-well culture plate for $24 \mathrm{~h}$. After overnight incubation, the medium was replaced with medium containing curcumin $(50 \mu \mathrm{g} / \mathrm{ml})$ and CM-NP $(137 \mu \mathrm{g} / \mathrm{ml})$. After $24 \mathrm{~h}$ incubation, the culture medium was discarded and $100 \mu$ of the stain solution (containing $2 \mu \mathrm{M}$ Calcein AM and $4 \mu \mathrm{M}$ of EthD-1 in PBS) was added for $30 \mathrm{~min}$ at $37{ }^{\circ} \mathrm{C}$. Images of live/dead cells were taken using a fluorescent microscope (Axiovert 200, Zeiss, Germany). The mean percentage of live cells was measured after analysis carried out by ImageJ software.

\section{Cytotoxicity Assay}

The cytotoxicity of curcumin and CM-NP were determined by the CytoTox-Fluor ${ }^{\mathrm{TM}}$ Cytotoxicity kit (Promega, Germany). The test measured dead-cell activity with crossing the 
fluorogenic peptide substrate (bis-alanyl-alanylphenylanlanyl-rhodamine 110) into the dead cells and giving the fluorescence signal [36]. GSCs $\left(1 \times 10^{4}\right.$ per well $)$ were cultured in medium with half maximal inhibitory concentration (IC50) of curcumin and CM-NP for $24 \mathrm{~h}$ at $37^{\circ} \mathrm{C}$. After overnight incubation, cytotoxicity assay reagent in an equal volume was added $(100 \mu \mathrm{l}$ per well) to all wells, mixed briefly by orbital shaking, and then incubated for at least $30 \mathrm{~min}$ at $37{ }^{\circ} \mathrm{C}$. Cytotoxicity was measured using a fluorescent plate reader (485 nm Ex/535 nm Em; PerkinElmer VICTOR X5, USA). The relative number of dead cells was indicated by analysis the activity of dead-cell protease activity released from dead cells with no membrane integrity.

\section{Cell Cycle Analysis}

GSCs were cultured in 6-well plates at a density of $1 \times 10^{6}$ cells per well overnight. Curcumin $(50$ and $200 \mu \mathrm{g} / \mathrm{ml})$ and CM-NP (137 and $411 \mu \mathrm{g} / \mathrm{ml}$ ) were then added and allowed to incubate for $24 \mathrm{~h}$. Cells were trypsinized, centrifuged at $2000 \mathrm{rpm}$ for $5 \mathrm{~min}$ at $4{ }^{\circ} \mathrm{C}$, suspended with ice-cold PBS, and fixed in $70 \%$ ethanol at $-20^{\circ} \mathrm{C}$ overnight. After fixation, GSCs were washed and re-suspended with ice-cold PBS. Then, cells were incubated with RNase A $(100 \mu \mathrm{l})$ for $30 \mathrm{~min}$ at room temperature. Next, the cells were resuspended in $400 \mu \mathrm{l} \mathrm{PI} /$ Triton X-100 solution $(50 \mu \mathrm{g} / \mathrm{ml} \mathrm{PI}$, $1 \mathrm{mg} / \mathrm{ml}$ sodium citrate, $0.1 \%$ Triton X-100) for $30 \mathrm{~min}$ in the dark. Next, cell cycle distribution was assessed from 10,000 cells in a BD FACSCALIBUR ${ }^{\text {TM }}$ FLOW CYTOMETER (Becton Dickinson, USA). DNA cell cycle analysis of flow cytometry data was performed by the software FlowJo V10 (Flowjo, OH, USA).

\section{Determination of Cell Death by Annexin V/PI Staining}

The quantity of apoptosis and necrosis induced by CM-NP against GSCs was measured by the Annexin V/PI staining kit (Cayman, USA). The GSCs were seeded at $1 \times 10^{6}$ cells per well on a 6-well plate and treated with curcumin (50 and $200 \mu \mathrm{g} / \mathrm{ml}$ ) and CM-NP (137 and $411 \mu \mathrm{g} / \mathrm{ml})$ for $24 \mathrm{~h}$. Next, cells were washed with $200 \mu \mathrm{l}$ of $1 \times$ binding buffer and centrifuged at $400 \mathrm{~g}$ for $5 \mathrm{~min}$. After that, $50 \mu \mathrm{l}$ of Annexin VFITC and PI reagent were added to the cells. The cells were incubated for $10 \mathrm{~min}$ in the dark at room temperature. Next, the final volume was set at $200 \mu \mathrm{l}$ with $1 \times$ binding buffer and the final volume was set at $250 \mu \mathrm{l}$ with $1 \times$ binding buffer. The number of viable, early apoptotic, late apoptotic, and necrotic cells was quantified immediately by the BD FACSCALIBUR TM FLOW CYTOMETER (Becton Dickinson, USA). The results were analyzed using the software FlowJo V10 (Flowjo, USA).

\section{Evaluation of Intracellular ROS}

Visualizing and quantitating the generation of ROS was performed by the DCFDA/H2DCFDA-cellular ROS detection assay kit according to the manufacturer's protocols (Abcam, UK). The GSCs were seeded at $25 \times 10^{3}$ cells per well on a 96well dark-sided culture plate. Then, the cells were washed with $1 \times$ buffer and received $100 \mu$ of H2DCFDA $(25 \mu \mathrm{M})$ media solutions ( $45 \mathrm{~min}$ in the dark). Then, cells were washed with PBS and incubated with IC50 concentration of curcumin and CM-NP for $8 \mathrm{~h}$. The mean fluorescence intensity generated by the H2DCFDA oxidation was evaluated at an excitation wavelength of $485 \mathrm{~nm}$ and an emission wavelength of $535 \mathrm{~nm}$ using a Victor X5 Multiplable Plate Reader (Perkin Elmer, USA). In addition, CM-NP-induced ROS activity was tested by fluorescent microscopy. Dissociated GSCs were then inserted on poly-L-lysine coated 96-well clear plates. IC50 concentrations of curcumin and CM-NP were added to cells for $4 \mathrm{~h}$. The cells were washed with PBS and H2DCFDA fluorescence was added to the cell and incubated for $30 \mathrm{~min}$. Images were obtained using a fluorescent microscope (Axiovert 200, Zeiss, Germany).

\section{Assessment of Gelatinases Using Gelatin Zymography}

The secretions of two members of the matrix metalloproteinases, MMP-2 and MMP-9, in culture conditioned medium were analyzed using gelatin zymography [37]. Briefly, the GSCs were treated with different doses of curcumin $(50$ and $200 \mu \mathrm{g} / \mathrm{ml})$ and CM-NP (137 and $411 \mu \mathrm{g} / \mathrm{ml}$ ) for $24 \mathrm{~h}$. Cultured media were centrifuged, the pellet was discarded, and $50 \mu \mathrm{g}$ of total protein from the supernatant was electrophoresed on $12 \%$ separating sodium dodecyl sulfate polyacrylamide gel electrophoresis containing $0.1 \%(1 \mathrm{mg} / \mathrm{ml})$ of gelatin. The gel was washed three times with washing buffer containing $2.5 \%$ Triton $\mathrm{X}-100$ every $20 \mathrm{~min}$ for three times and then incubated for $24 \mathrm{~h}$ at $37^{\circ} \mathrm{C}$ in the incubation buffer (2.5\% Triton X-100 in $50 \mathrm{mM}$ Tris pH 7.4, $5 \mathrm{mM} \mathrm{CaCl} 2,1 \mu \mathrm{M} \mathrm{ZnCl} 2)$. The gel was stained with $0.5 \%$ Coomassie Brilliant Blue R-250, 40\% ethanol, and 2\% acetic acid in $\mathrm{dH} 2 \mathrm{O}$ for $30 \mathrm{~min}$, and then de-stained with $25 \%$ ethanol and $10 \%$ acetic acid in $\mathrm{dH} 2 \mathrm{O}$. The gelatinolytic activity (zones of gelatin degradation) was assessed by GS-800 calibrated densitometer (Bio-RAD, USA). The analysis was performed by using Image J 1.52a software (NIH, USA).

\section{Quantitative Real-time Polymerase Chain Reaction Assessments}

Total RNA extraction of the treated cells $\left(7 \times 10^{5}\right.$ cells per well, in 6-well plates) was performed according to the RNeasy® mini kit protocol (Qiagen, Germany). The quantification and quality control of extracting RNA was conducted in triplicate with a NanoDrop spectrophotometer (Thermo Fisher 
Scientific, Germany). Then, RNAs were reverse-transcribed using the RevertAid First Strand cDNA Synthesis (Thermo Fisher Scientific, Germany). The quantitative RT-PCR analysis was performed by RealQ Plus 2X MasterMix Green-without Rox $^{\text {TM }}$ (Amplicon, Denmark). Next, quantitative RT-PCR was carried out with specific primers for p53, Bax, Bcl-2, NF-kB, IL6 (Santa Cruz, Germany), monocyte chemoattractant protein-1 (MCP-1), and CXCL-3 (Macrogene, Korea). The cDNA amplification was conducted using the Light-Cycler 96 real-time PCR system (Roche Applied Science, USA). Gene expression data were normalized to GAPDH. The $2^{-\Delta \Delta \mathrm{Ct}}$ method was used to analyze the relative expression of target genes. The primer sequences (forward and reverse) are listed in Table 1.

\section{Migration Assay}

GSCs migration was evaluated by a wound healing assay as described previously [38]. After 72-h incubation, GSCs reached $90 \%$ confluence. A straight line scratch on cell monolayer was done with a sterile $100-\mu$ l pipette tip. PBS washing was performed to remove the debris. The cells were then treated with curcumin $(6.25$ and $12.5 \mu \mathrm{g} / \mathrm{ml})$ and CM-NP (17.12 and $34.25 \mu \mathrm{g} / \mathrm{ml}$ ) and incubated for $72 \mathrm{~h}$. The lesion border areas were observed and photographed using an inverted microscope (ZEISS Axiovert 200, Zeiss, Germany). GSCs migration distance was calculated at $4,24,48$, and $72 \mathrm{~h}$.

\section{Clonogenicity Assay}

To evaluate anchorage-independent tumor growth potential, colony formation assay was conduct using soft agar (Merck, Germany). Single cells $\left(15 \times 10^{3}\right.$ per well $)$ were seeded on agarose-coated 96-well flat bottom plates. Colonies were formed in 3 days and then were treated with $50 \mu \mathrm{g} / \mathrm{ml}$ of curcumin as well as $137 \mu \mathrm{g} / \mathrm{ml}$ of CM-NP for 5 days. The images were taken by an inverted microscope (Axiovert 200, Zeiss, Germany).

\section{Immunohistochemistry}

To study the effect of curcumin and CM-NP on the expression of brain tumor stem cell markers, immunocytochemistry was performed according to a previously described method [39]. Briefly, GSCs were grown on poly-D-lysine 96-well plates and treated with curcumin $(25 \mu \mathrm{g} / \mathrm{ml})$ and CM-NP $(68.5 \mu \mathrm{g} / \mathrm{ml})$ and incubated for $72 \mathrm{~h}$. GSCs were washed with PBS and fixed with $4 \%$ formaldehyde for $30 \mathrm{~min}$ and then were permeabilized by incubation with $0.2 \%$ Triton X-100 (in PBS) for 10 min at room temperature. Non-specific bindings were blocked through incubation with $1.5 \%$ goat serum and $1 \%$ bovine serum albumin (Sigma, Germany) in PBS for 30 min at room temperature. Primary antibodies, including nestin (1:250, Abcam, USA) and Sox2 (1:250, Abcam, USA) as the markers for cancer stem cells, were used. Secondary antibody (goat anti-rabbit IgG conjugated to FITC) was applied for $1 \mathrm{~h}$ at $4{ }^{\circ} \mathrm{C}$. Propidium iodide (Sigma-Aldrich, USA) was used to detect cell nuclei. Data were analyzed using fluorescent microscopy (ZEISS Axiovert 200, Zeiss, Germany).

\section{Statistical Analysis}

Analyses were conducted by GraphPad Prism software (version 17). Statistically significant differences between different groups were assessed using one-way analysis of variance (ANOVA). Post hoc multiple comparisons were conducted by Tukey's tests. Statistical analysis of migration assay data was performed by two-way repeated-measure ANOVAs with Tukey's post hoc

Table 1 Summary of primers

\begin{tabular}{|c|c|c|}
\hline Gene symbol & Gene name & Primers $\left(5^{\prime} \rightarrow 3^{\prime}\right)$ \\
\hline $\mathrm{BAX}$ & BCL2 associated X, apoptosis regulator & $\begin{array}{l}\text { Forward: GGAGCTGCAGAGGATGATTG } \\
\text { Reverse: CCAGTTGAAGTTGCCGTCAC }\end{array}$ \\
\hline $\mathrm{Bcl}-2$ & BCL2 apoptosis regulator & $\begin{array}{l}\text { Forward: CTGAGGAGCTTTGTTTCAACCA } \\
\text { Reverse: TCAAGAAACAAGGTCAAAGGGA }\end{array}$ \\
\hline p53 & Tumor protein p53 & $\begin{array}{l}\text { Forward: ACCCTTGCTTGCAATAGGTG } \\
\text { Reverse: AACAAAACACCAGTGCAGGC }\end{array}$ \\
\hline MCP-1 & Monocyte chemoattractant protein 1 & $\begin{array}{l}\text { Forward: CATGAAAGTCTCTGCCGCC } \\
\text { Reverse: GGTGACTGGGGCATTGATTG }\end{array}$ \\
\hline $\mathrm{NF}-\kappa \mathrm{B}$ & Nuclear factor-kappa B & $\begin{array}{l}\text { Forward: GCGAGAGGAGCACAGATACC } \\
\text { Reverse: CTGATAGCCTGCTCCAGG }\end{array}$ \\
\hline CXCL3 & Chemokine (C-X-C motif) ligand 3 & $\begin{array}{l}\text { Forward: CGCCCAAACCGAAGTCATAG } \\
\text { Reverse: GCTCCCCTTGTTCAGTATCTTTT }\end{array}$ \\
\hline$I L-6$ & Interleukin 6 & $\begin{array}{l}\text { Forward: CCTGAACCTTCCAAAGATGGC } \\
\text { Reverse: TTCACAAGGCAAGTCTCCTCA }\end{array}$ \\
\hline GAPDH & Glyceraldehyde-3-phosphate dehydrogenase & $\begin{array}{l}\text { Forward: ACAACTTTGGTATCGTGGAAGG } \\
\text { Reverse: GCCATCACGCCACAGTTTC }\end{array}$ \\
\hline
\end{tabular}


Fig. 2 Characterization of curcumin-encapsulated noisome nanoparticle (CM-NP). a Size of curcumin (CM, left) and CM-NP (right) was measured by transmission electron microscopy (TEM). TEM images showed particles with a spherical morphology and an average size of $60 \mathrm{~nm}$. b In vitro release profile of CM-NP was assessed in PBS at physiological $\mathrm{pH}$ (7.4). The release of $\mathrm{CM}$ from the niosome was $\sim 14 \%$ at $24 \mathrm{~h}$. c Interaction between components of CM-NP was evaluated by fourier transform infrared (FTIR) spectra. FTIR analysis indicated four peaks at $3860 \mathrm{~cm}^{-1}, 2916 \mathrm{~cm}^{-1}$, $1738 \mathrm{~cm}^{-1}$, and $1104 \mathrm{~cm}^{-1}$, which were corresponding to cholesterol, Tween 60, Span 60, and C-O $\mathrm{C}$ interactions, respectively. $\mathbf{d}$ Differential scanning calorimetry (DSC) thermograms of CM-NP were assessed between 5 and $60{ }^{\circ} \mathrm{C}$. DSC analysis pointed to the stability of CM-NP at body temperature
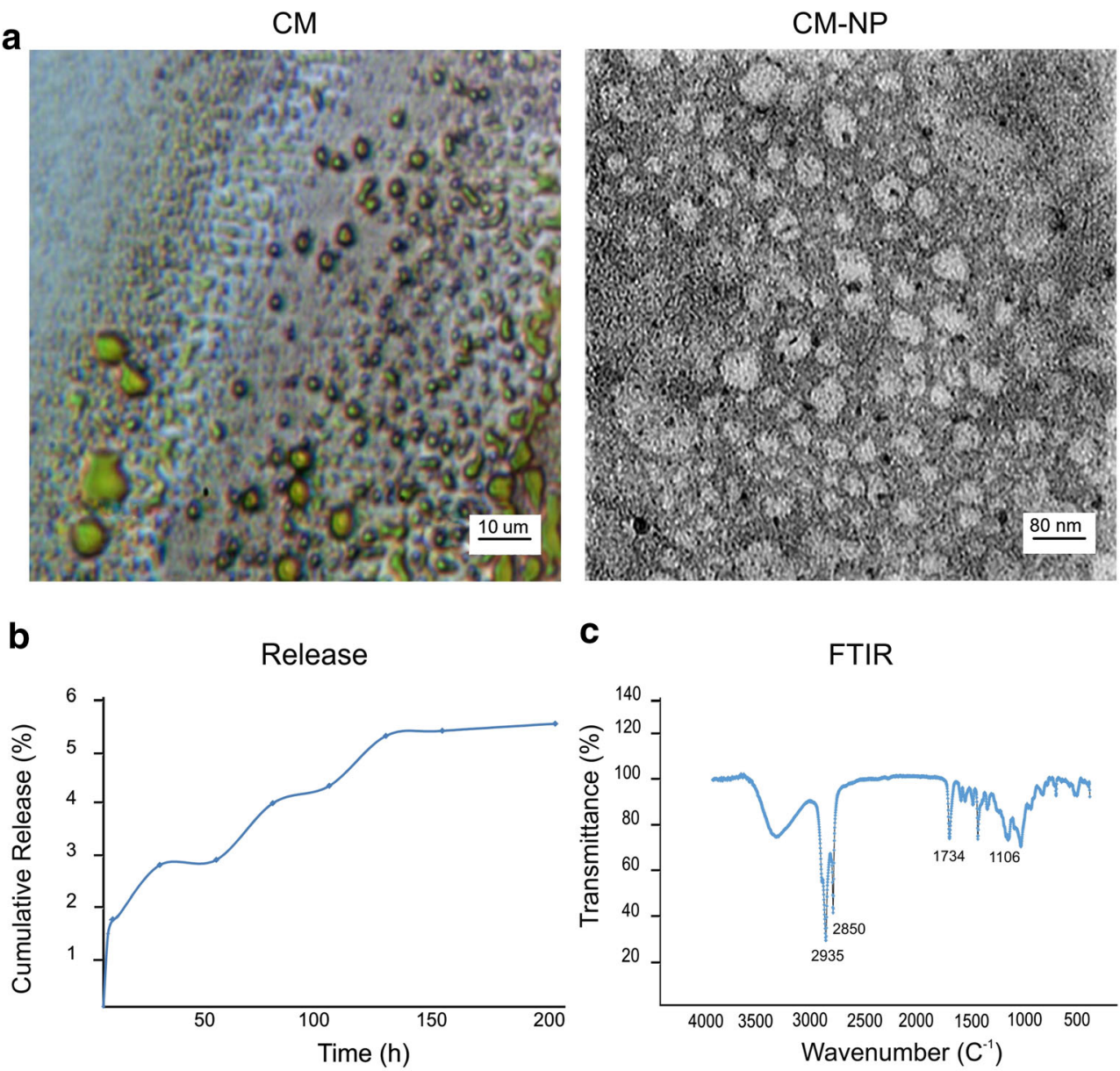

C
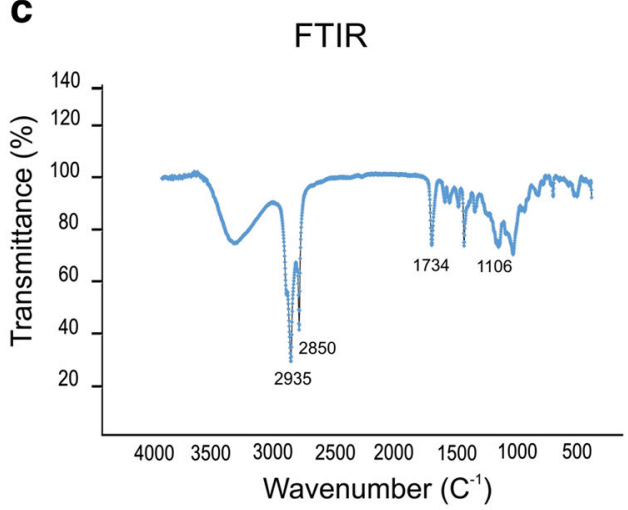

DSC

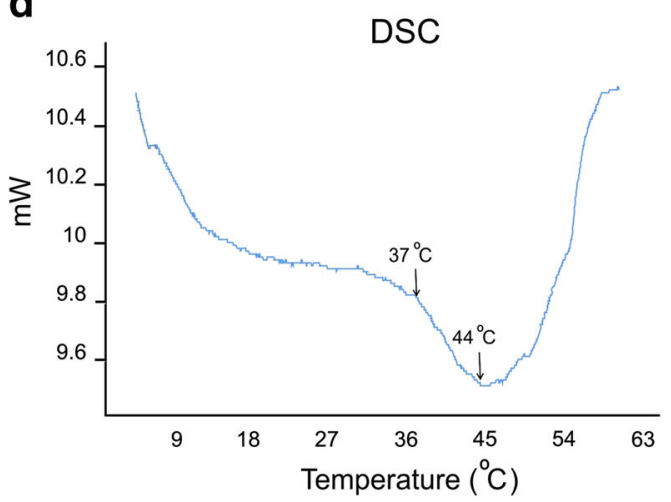

tests. Data were presented as the mean \pm standard deviation and the significance level was considered at $P<0.05$.

\section{Results}

\section{Nano-drug Characterization}

To develop an effective curcumin delivery system, we constructed curcumin-loaded niosome nanoparticle using the thin-film hydration method. TEM images indicated that nanoparticles have a monodisperse size distribution with a diameter of $\sim 60 \mathrm{~nm}$ (Fig. 2a). Using DLS method, the average size of CM-NP was $\sim 90 \mathrm{~nm}$ and the heterogeneity index was $0.2 \pm$ 0.002 . Successful formulation of CM-NP is further examined by the surface zeta potential of nanoparticles in deionized water. The zeta potential of niosome nanoparticles was $\sim-$ $35 \mathrm{mV}$, indicating that the CM-NP has a good stability. The entrapment efficiency of CM-NP was $\sim 80 \%$. The in vitro release profile of the loaded curcumin from the niosome 
a
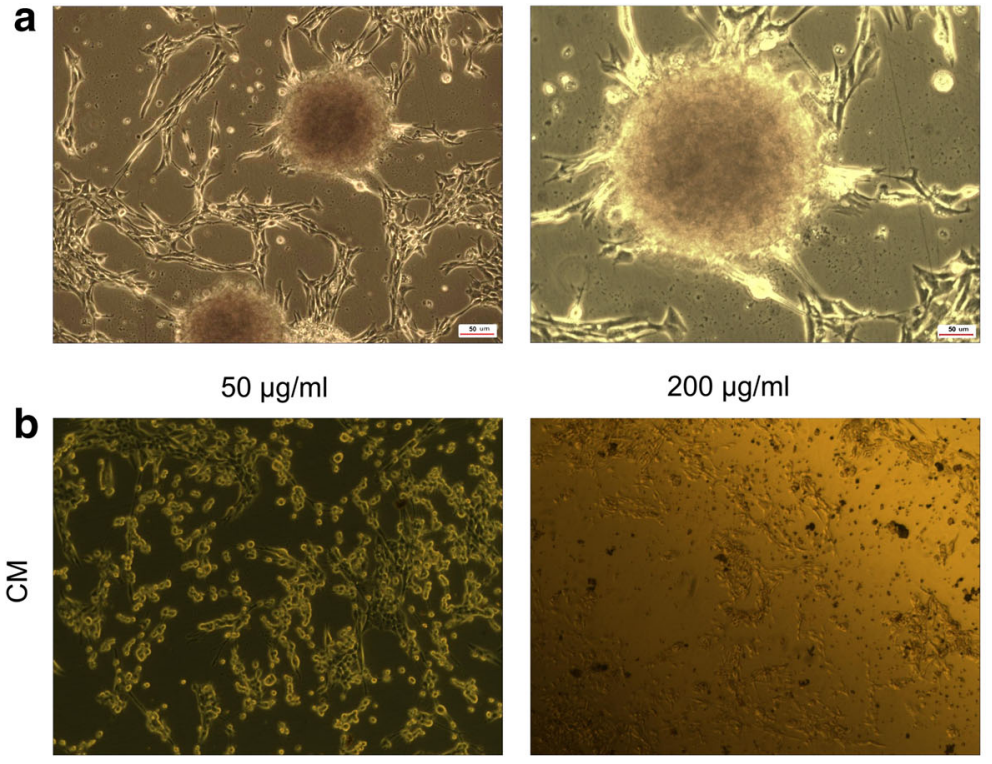

$200 \mu \mathrm{g} / \mathrm{ml}$
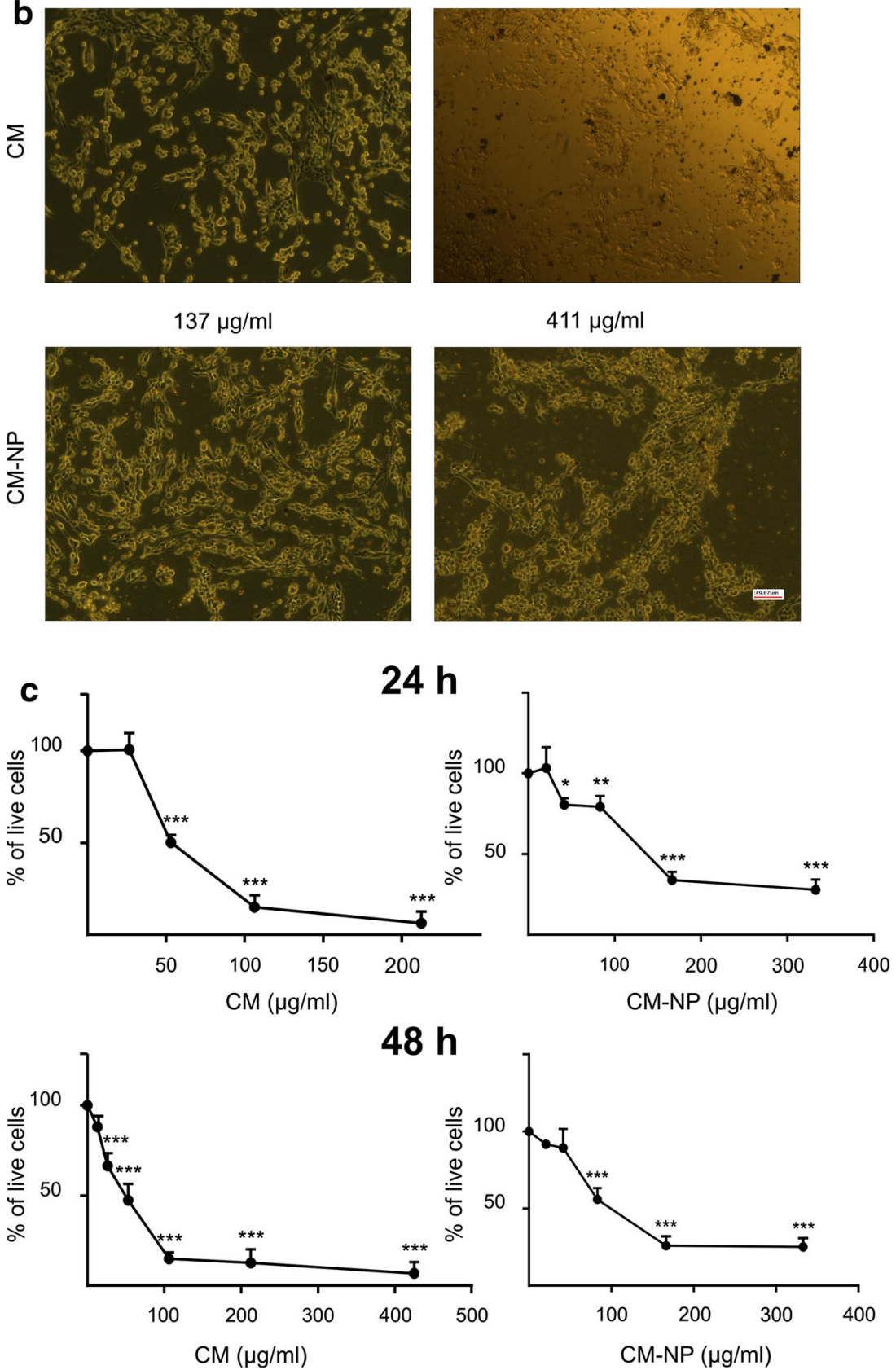

nanoparticles indicates an initial release of only $14.5 \%$ of curcumin after $24 \mathrm{~h}$ (Fig. 2b). Release profile of curcumin from niosome nanoparticles reached in a sustained pattern over time, indicating high stability of CM-NP.
To determine the interaction between different components of CM-NP, FTIR spectra were performed. As shown in Fig. 2c, FTIR spectrum showed the peaks at $3860 \mathrm{~cm}^{-1}, 2916 \mathrm{~cm}^{-1}, 1738 \mathrm{~cm}^{-1}$, and $1104 \mathrm{~cm}^{-1}$, 
Fig. 3 Cytotoxic effects of curcumin (CM) and curcumin-encapsulated noisome nanoparticle (CM-NP) on glioblastoma stem-like cells (GSCs). a Representative phase contrast micrographs of neurosphere formation of GSCs. b Phase contrast images of GSCs following 24-h treatment with $\mathrm{CM}(50$ and $200 \mu \mathrm{g} / \mathrm{ml})$ and CM-NP (137 and $411 \mu \mathrm{g} / \mathrm{ml})$. c Cytotoxicity of CM and CM-NP on GSC proliferation was assessed by the MTT assay. To determine the half maximal inhibitory concentration (IC50) of drugs, the percentage of live GSCs was measured after 24- and 48-h treatment with different concentrations of CM and CM-NP. The data are presented as means $\pm \mathrm{SD}$. Single, double, and triple asterisks indicate $P<0.05, P<$ 0.01 , and $P<0.001$, respectively

which were corresponding to cholesterol, Tween 60 , Span 60 , and niosome formation of $\mathrm{C}-\mathrm{O}-\mathrm{C}$ interactions, respectively. Thermal characterization was also performed using differential scanning calorimetry. The DSC thermogram displayed a sharp endothermic peak at $45{ }^{\circ} \mathrm{C}$, which corresponds to the melting of the CM-NP (Fig. 2d). DSC thermogram of CM-NP powder exhibited sufficient stability at $37{ }^{\circ} \mathrm{C}$. These results revealed a significant interaction of curcumin with the shell structure of niosome, enhanced entrapment of curcumin into niosomal formulations, and sustained drug release.

\section{GSC Culture}

To evaluate the self-renewal ability and the proliferation capacity, GSCs were passaged for 4 times (each time reached $80 \%$ confluence). The tumor stem-like single cells produced

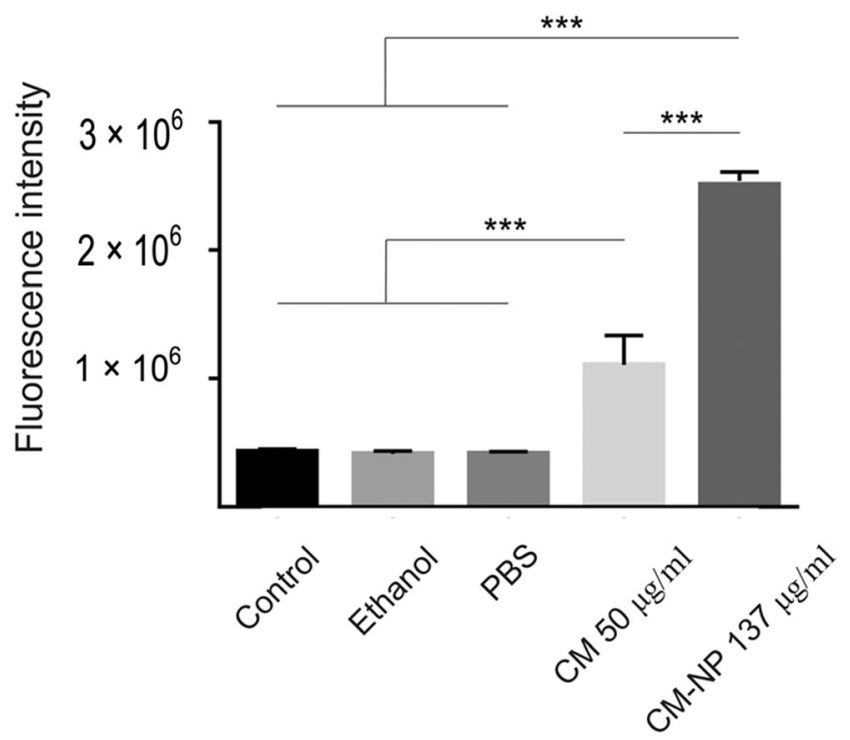

Fig. 4 Analysis of cytotoxicity of curcumin (CM) and curcuminencapsulated noisome nanoparticle (CM-NP) on glioblastoma stem-like cells (GSCs). The relative number of dead cells was identified by the amount dead-cell protease activity using a fluorogenic peptide substrate crossing into the dead cells. The values are expressed as mean $\pm \mathrm{SD}$. Triple asterisks indicate $P<0.001$ spheres after 6 days, which could be passaged for 4-5 times, indicating self-renewal property of GSCs in spheres (Fig. 3a).

\section{Tumor Growth Results}

\section{CM-NP Inhibits Cell Proliferation and Viability of GSCs}

The effects of different doses of curcumin and CM-NP on GSCs morphology were investigated. Application of curcumin and CM-NP treatment caused shrinkage and partial detachment of GSCs after $24 \mathrm{~h}$, pointing to the cytotoxic effects of CM-NP (Fig. 3b). The functional effects of curcumin and CM-NP on cell proliferation of the GSCs were assessed by MTT assay. GSCs were incubated with different concentrations of curcumin and CM-NP and cell proliferation was assessed after 24 and 48 h. As shown in Fig. 3c, both curcumin and CM-NP significantly inhibited the proliferation of GSCs in a time- and dose-dependent manner. The IC50 value of CM-NP on GSCs was $137 \mu \mathrm{g} / \mathrm{ml}$ after $24 \mathrm{~h}$, which decreased to $101 \mu \mathrm{g} / \mathrm{ml}$ after $48 \mathrm{~h}$ (Fig. 3c). Our results also showed that IC50 values of curcumin on GSCs were $50 \mu \mathrm{g} / \mathrm{ml}$ and $43 \mu \mathrm{g} / \mathrm{ml}$ after 24 and $48 \mathrm{~h}$, respectively (Fig. 3c). For further experiments, mostly the values of $50 \mu \mathrm{g} / \mathrm{ml}$ and $137 \mu \mathrm{g} / \mathrm{ml}$ were chosen to investigate the effects of curcumin and CM-NP, respectively.

To detect the relative number of dead cells, the effects of curcumin and CM-NP on proteolytic activities associated with GSCs death were measured. CM-NP significantly enhanced the activity of proteases compared with free curcumin and the control groups (Fig. $4 ; P<0.001$ ). Furthermore, the cytotoxicity induced by curcumin and CM-NP on cell viability of GSCs was tested using live/dead assay (Fig. 5a). GSCs treated with curcumin and CM-NP were harvested after $24 \mathrm{~h}$ and were subjected to viability assay. Cell viability of GSCs significantly decreased after administration of CM-NP compared with curcumin $(P<0.05)$ and the control groups (Fig. 5b; $P<$ $0.001)$. Furthermore, curcumin significantly decreased cell viability compared with the control group (Fig. 5b; $P<0.05$ ). To establish whether curcumin and CM-NP at different doses were toxic to normal cells, NIH-3T3 cells were treated with these compounds for $24 \mathrm{~h}$. Both curcumin and CM-NP exhibited dose-dependent effects on cell survival of NIH-3T3 cells. Administration of curcumin at a concentration above $12.5 \mu \mathrm{g} / \mathrm{ml}$ was associated with $50-80 \%$ loss of NIH-3T3 cells (Fig. 6). However, cell viability of NIH-3T3 cells following application of CM-NP at concentrations between 100 and $150 \mu \mathrm{g} / \mathrm{ml}$ was $\sim 70 \%$ (Fig. 6).

\section{CM-NP Induces Apoptosis and Necrosis in GSCs}

We further examined both cell cycle and apoptosis parameters in curcumin- and CM-NP-treated GSCs. Cell cycle analysis showed that the application of high doses of CM-NP on GSCs 
Fig. 5 Live/dead assay of glioblastoma stem-like cells (GSCs) treated with IC50 concentration of curcumin $(\mathrm{CM})$ and curcumin-encapsulated noisome nanoparticle (CM-NP). a Living cells are labeled green (Calcein AM) and dead cells are labeled red (ethidium homodimer) after treatment with CM $(50 \mu \mathrm{g} / \mathrm{ml})$ and CM-NP $(137 \mu \mathrm{g} / \mathrm{ml})$. b Quantitative analyses of GSC viability in different groups are shown. The values are expressed as mean \pm . Single and triple asterisks indicate $P<0.05$ and $P<$ 0.001 , respectively
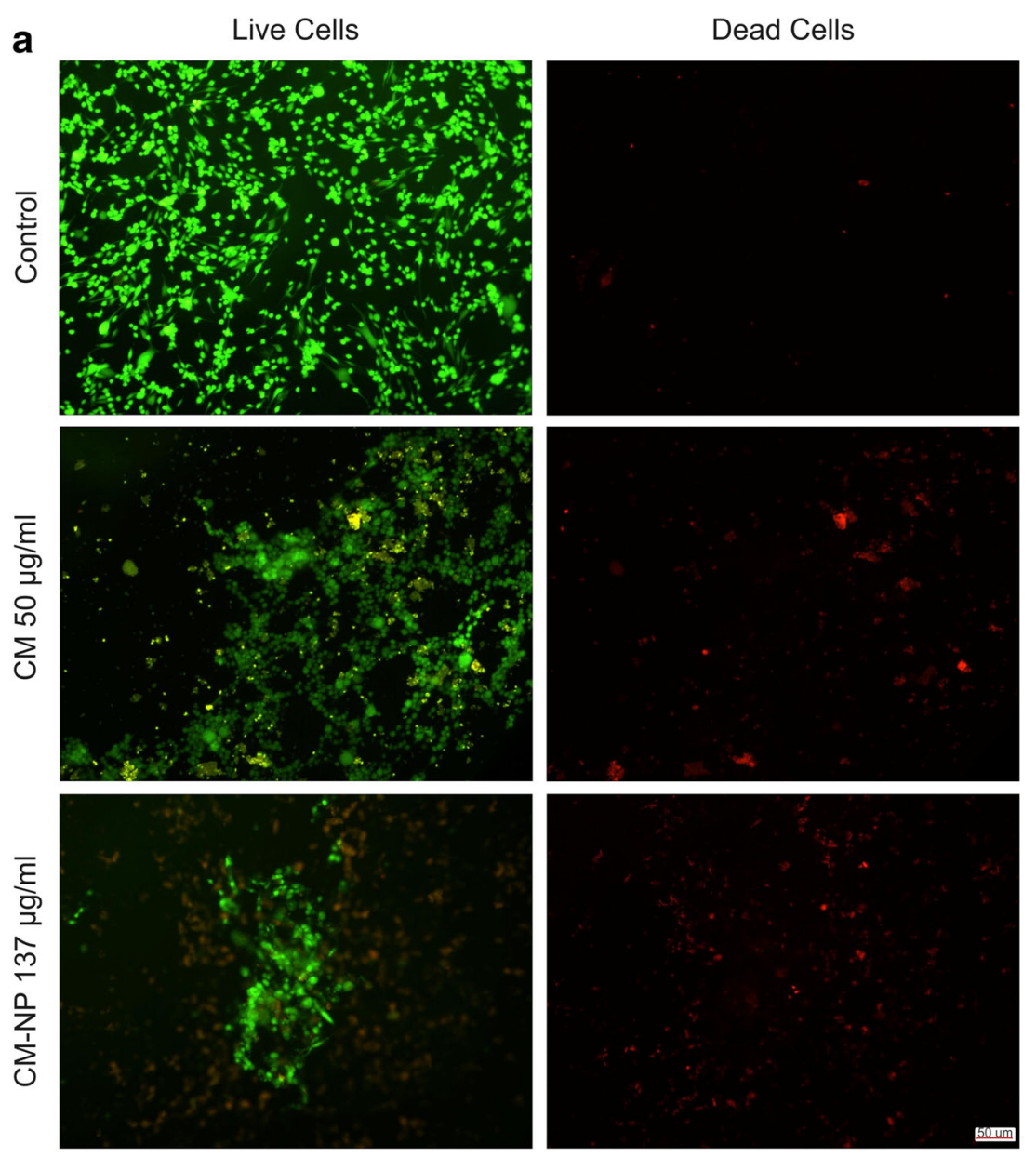

b

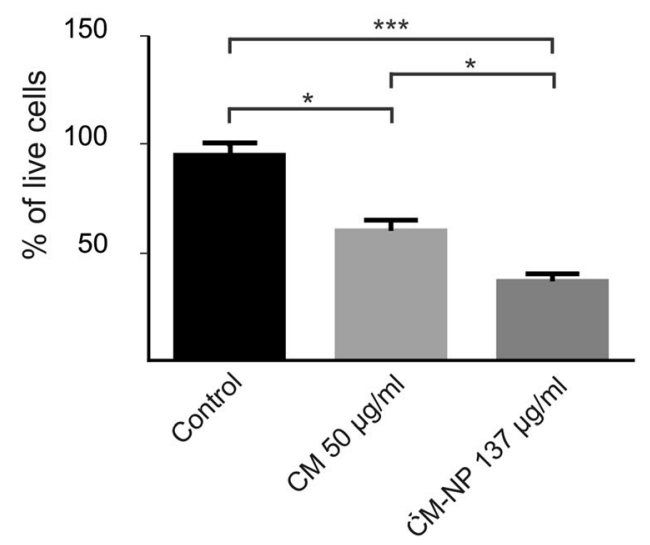

PI-positive cells. The percentage of GSCs in the late apoptotic stage after application of curcumin at concentrations of 50 and $200 \mu \mathrm{g} / \mathrm{ml}$ was about 91.9 and $92.7 \%$, respectively. In contrast to curcumin, the number of necrotic cells was significantly increased when GSCs were exposed to CM-NP. Flow cytometry analysis revealed that the percentage of late apoptotic and necrotic GSCs following administration of CM-NP at $137 \mu \mathrm{g} / \mathrm{ml}$ was $65.7 \%$ and $23 \%$, respectively. CM-NP at $411 \mu \mathrm{g} / \mathrm{ml}$ 
Fig. 6 The effects of curcumin (CM) and curcumin-encapsulated noisome nanoparticle (CM-NP) on viability of NIH-3T3 cells. NIH-3T3 cells were incubated with different concentrations of $\mathrm{CM}$ and CM-NP for $24 \mathrm{~h}$. The MTT assay was used to determine cell viability of CM- and CM-NPtreated cells. The data are presented as mean $\pm \mathrm{SD}$. Double and triple asterisks indicate $P<0.01$ and $P<0.001$, respectively
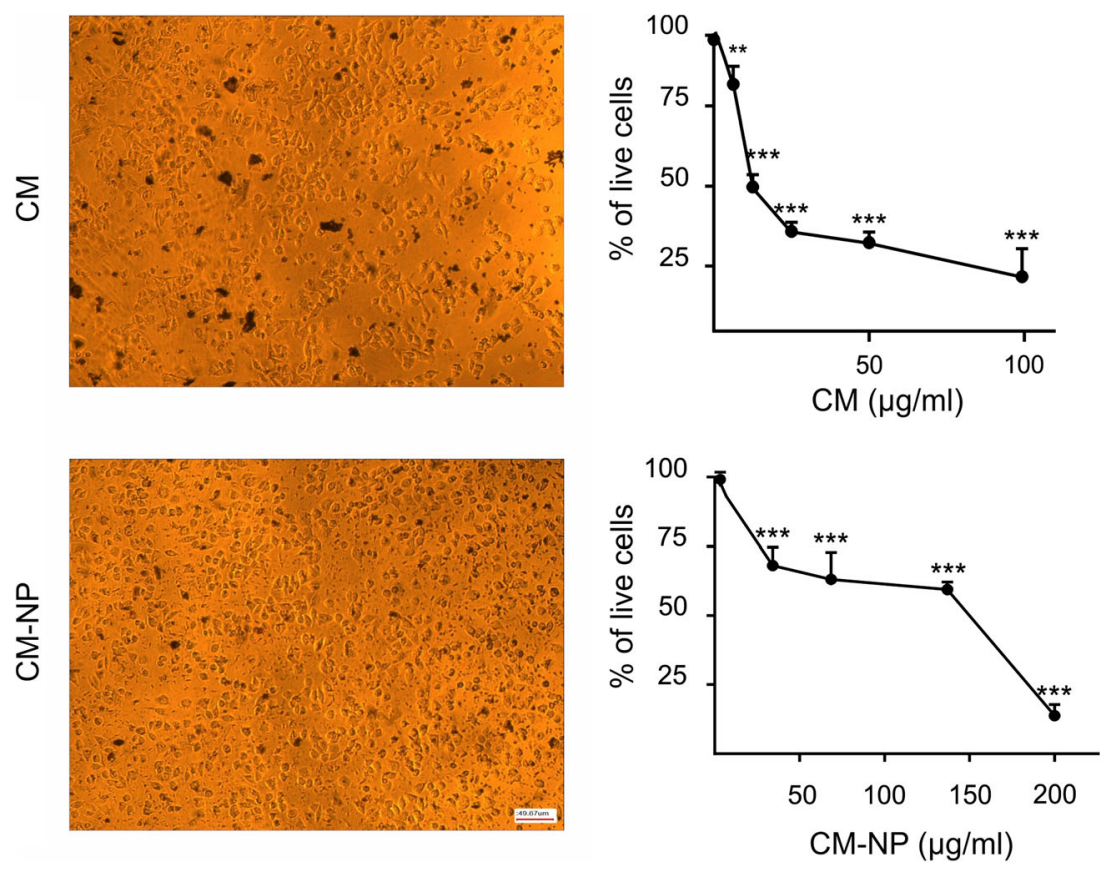

Control

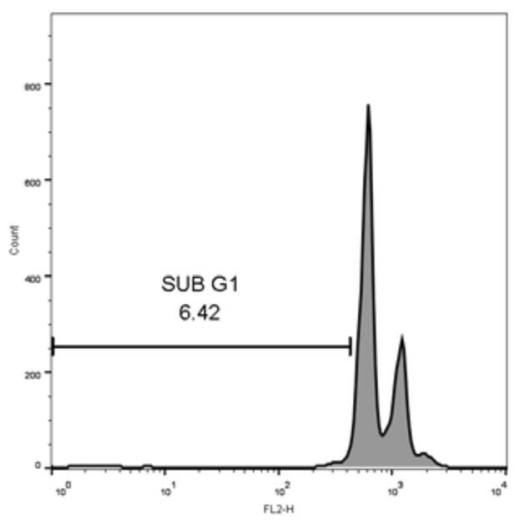

CM $50 \mu \mathrm{g} / \mathrm{ml}$

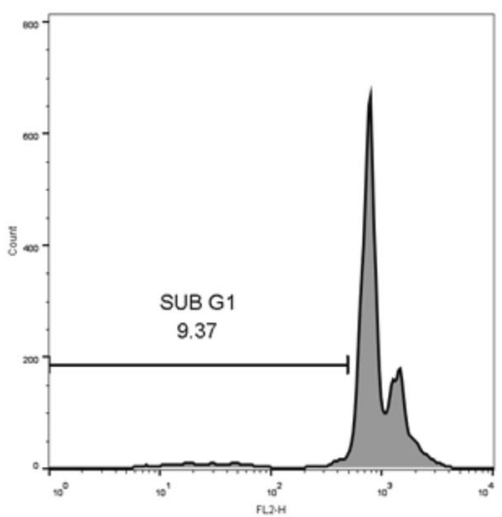

CM $200 \mu \mathrm{g} / \mathrm{ml}$

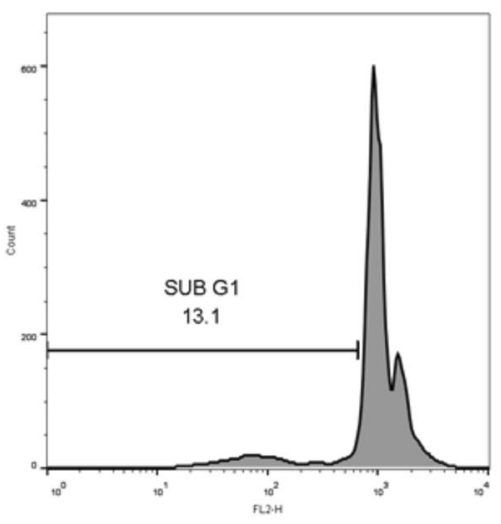

CM-NP $411 \mu \mathrm{g} / \mathrm{ml}$

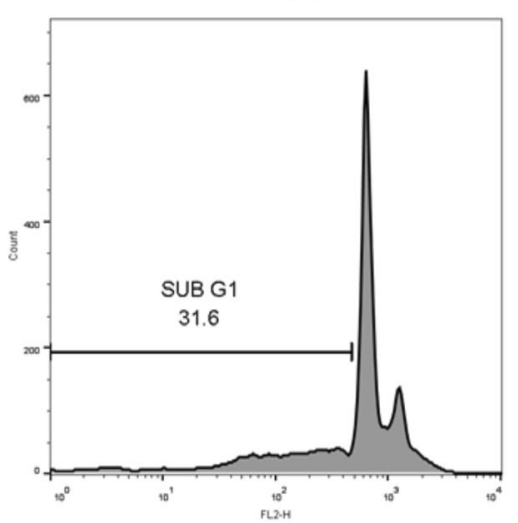

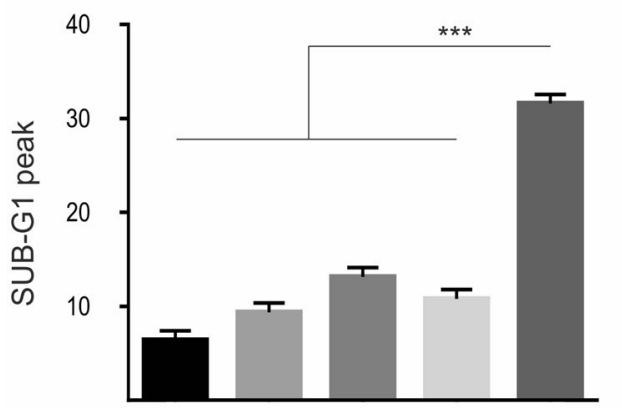

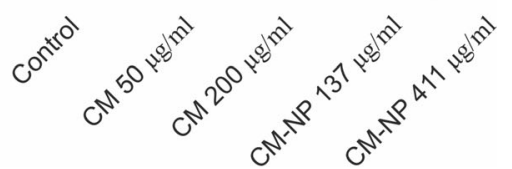

Fig. 7 The effects of curcumin (CM) and curcumin-encapsulated noisome nanoparticle (CM-NP) on glioblastoma stem-like cells (GSCs) cell cycle. GSCs treated with different concentrations of CM and CM-NP for $24 \mathrm{~h}$ were stained with propidium iodide (PI) and the cell cycle was assessed using flow cytometry. The cell cycle was determined in GSCs treated with $\mathrm{CM}(50$ and $200 \mu \mathrm{g} / \mathrm{ml})$ and CM-NP $(137$ and $411 \mu \mathrm{g} / \mathrm{ml})$ as well as in the control group (non-treated GSCs). Note the strong effect of CM-NP at $411 \mu \mathrm{g} / \mathrm{ml}$ on cell cycle arrest compared with the other groups. The data represent as the mean $\pm \mathrm{SD}$. Triple asterisks indicate $P<0.001$ 

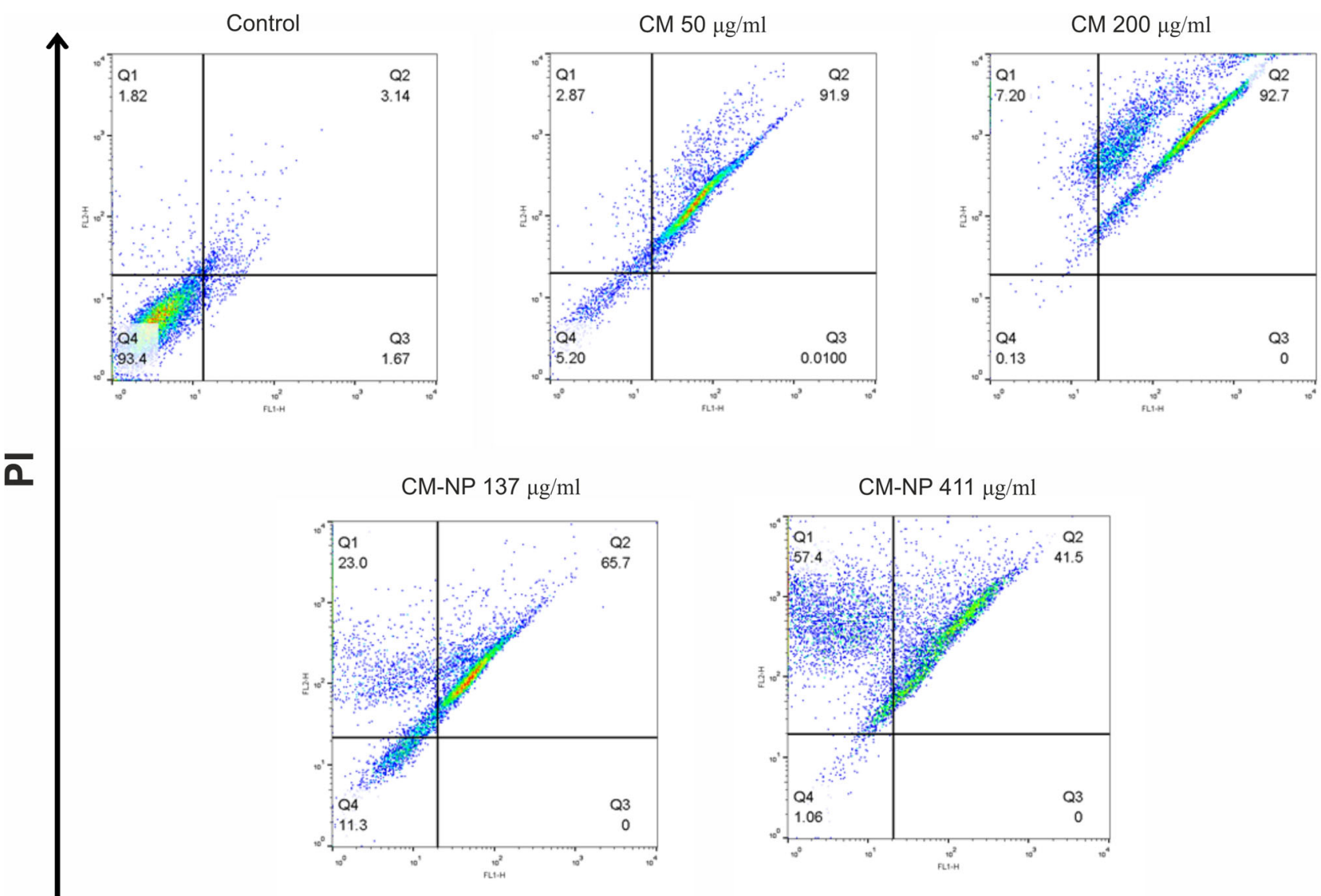

\section{Annexin V}

Fig. 8 The effects of curcumin (CM) and curcumin-encapsulated noisome nanoparticle (CM-NP) on apoptosis of glioblastoma stem-like cells (GSCs). GSCs were double-stained with Annexin V/ propidium iodide and assessed by flow cytometry to determine apoptosis of GSCs treated with CM (50 and $200 \mu \mathrm{g} / \mathrm{ml})$ and CM-NP (137 and $411 \mu \mathrm{g} / \mathrm{ml})$.
Untreated cells were indicated as control. Diagrams quarter $1(\mathrm{Q} 1)$ to Q4 indicate necrotic, late apoptotic, early apoptotic, and live cells, respectively. Cells treated with CM-NP exhibited a higher amount of necrotic GSCs

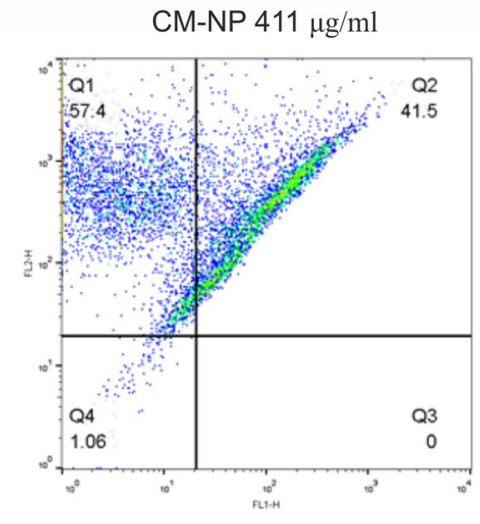

enhanced the percentage of necrotic cells to $57.4 \%$ (Fig. 8). Our results indicate that CM-NP more efficiently induces cell arrest and increases cell apoptosis and necrosis in GSCs compared with free curcumin.

\section{CM-NP Modulates Molecular Signaling of Apoptosis}

Alterations in the expression of $\mathrm{p} 53, \mathrm{Bax}, \mathrm{Bcl} 2, \mathrm{NF}-\mathrm{kB}$, and IL-6 in GSCs were analyzed using real-time PCR. P53mediated apoptosis and cell cycle arrest in cancer cells is suggested a desirable outcome of tumor therapy [40]. Curcumin significantly increased the expression level of P53, whereas no changes in the expression levels of $\mathrm{p} 53$ were observed after CM-NP treatment (Fig. 9; $P<0.001$ ). Following 24-h treatment with CM-NP, the mRNA levels of Bax significantly increased compared with the free curcumin and untreated control group (Fig. 9; $P<0.001$ ). Both curcumin and CM-NP significantly decreased the mRNA levels of Bcl2 compared with the control group (Fig. 9; $P<0.001$ ). No significant differences were observed in the expression levels of Bcl2 between the curcumin and CM-NP groups. The NF-kB-IL-6 signaling pathway plays a crucial role in tumor cell proliferation and apoptosis [41]. The values of NF- B and IL-6 following treatment with CM-NP were significantly lower than the curcumin and control groups (Fig. 9; $P<0.001$ ). NF- B and IL-6 levels were significantly higher in the curcumin-treated GSCs compared with the control group (Fig. 9; $P<0.001$ ).

\section{CM-NP Increases the Production of ROS}

Curcumin has been suggested to inhibit tumor growth via upregulation of ROS values [42]. The levels of ROS were significantly increased in the CM-NP-treated group compared with the curcumin and control groups (Fig. 10a and b; $P<$ $0.001)$. Increasing the time of incubation and dose of CM-NP led to an increase in the levels of ROS in GSCs (data not 
Fig. 9 The effects of curcumin (CM) and curcumin-encapsulated noisome nanoparticle (CM-NP) on the mRNA expression levels of apoptotic markers p53, Bax, and $\mathrm{Bcl} 2$ as well as on chemokines NF- $\mathrm{kB}$, and IL- 6 of glioblastoma stem-like cells (GSCs). CM-NP significantly enhanced $\mathrm{Bax}$ and decreased $\mathrm{Bcl} 2$, NF-KB, and IL-6 compared with the control group. CM significantly increased the expression of p53 compared with the CM-NP and control groups, whereas CM$\mathrm{NP}$ did not regulate $\mathrm{p} 53$. All data represent as the mean $\pm \mathrm{SD}$. Triple asterisks indicate $P<0.001$

\section{p53}

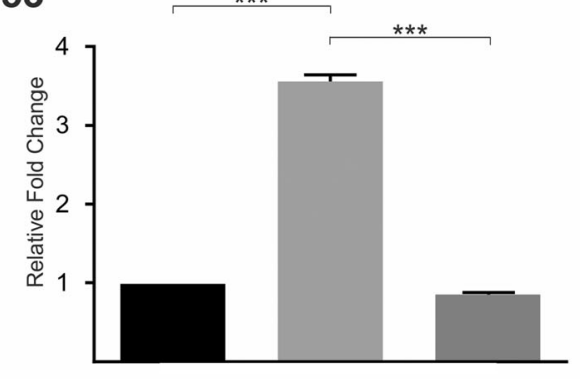

Bax
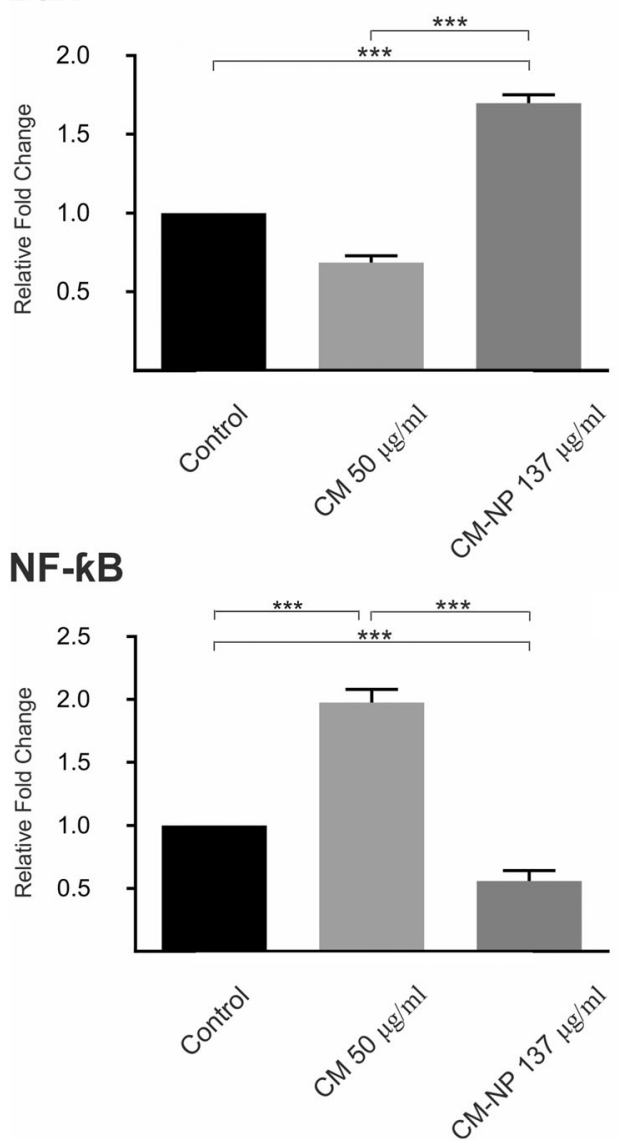

$\mathrm{Bcl} 2$

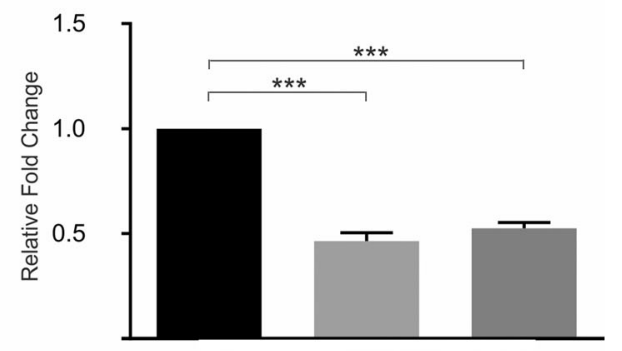

IL-6

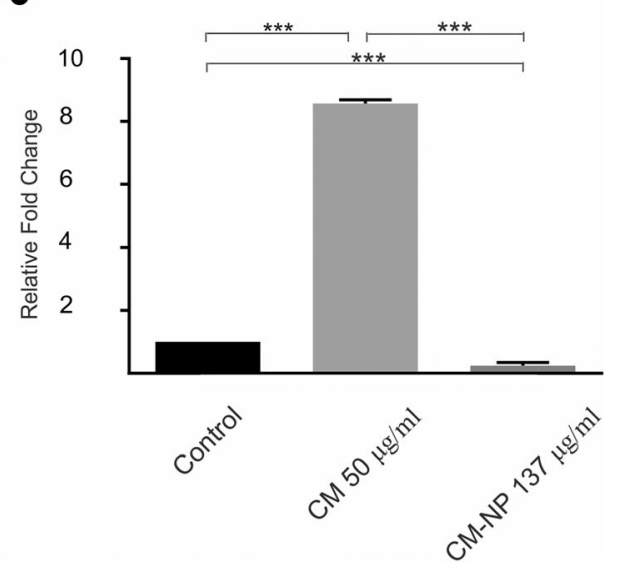

shown). The effects of CM-NP on the levels of ROS were time-dependent.

\section{Migration and Invasion Properties}

\section{CM-NP Inhibits the Migration of GSCs}

To compare the inhibitory effects of free curcumin and CMNP on GSC migration, we performed the scratch wound healing assay. CM-NP at $34.25 \mu \mathrm{g} / \mathrm{ml}$ significantly inhibited the migration of GSCs after $48 \mathrm{~h}$ and $72 \mathrm{~h}$ of application compared with the curcumin and control groups (Fig. 11a and $\mathrm{b} ; P<0.05)$. However, curcumin at different doses did not affect GSC migration. Therefore, our results showed that the inhibitory effects of curcumin increased when formulated in niosome nanoparticles.

\section{CM-NP Suppresses MMP-2}

MMP-2 regulates cancer cell behaviors, including tumor growth and migration [43]. To evaluate the effect of curcumin and CM-NP on the secretion of MMP-2 and MMP-9, GSCs 
Fig. 10 The effects of curcumin (CM) and curcumin-encapsulated noisome nanoparticle (CM-NP) on the generation of reactive oxygen species (ROS) in glioblastoma stem-like cells (GSCs). a Photomicrographs of curcumin-, CM-NP-, and tert-Butyl hydroperoxide (TBHP)-mediated ROS production in GSCs were obtained under fluorescence microscopy. b ROS induction in GSCs after $8 \mathrm{~h}$ application of CM, CM$\mathrm{NP}$, and TBHP as well as in the control group was determined by measuring fluorescent intensities in a microplate reader. Note a significant higher generation of ROS by application of CM-NP compared with the CM and control groups. Data are expressed as the mean $\pm \mathrm{SD}$. Triple asterisks indicate $P<0.001$

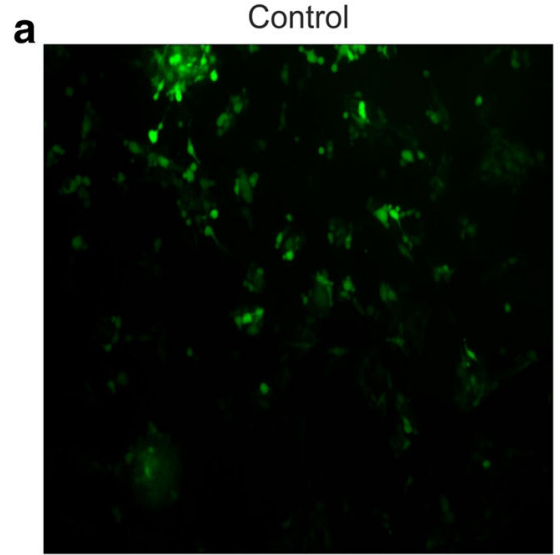

CM-NP $137 \mu \mathrm{g} / \mathrm{ml}$

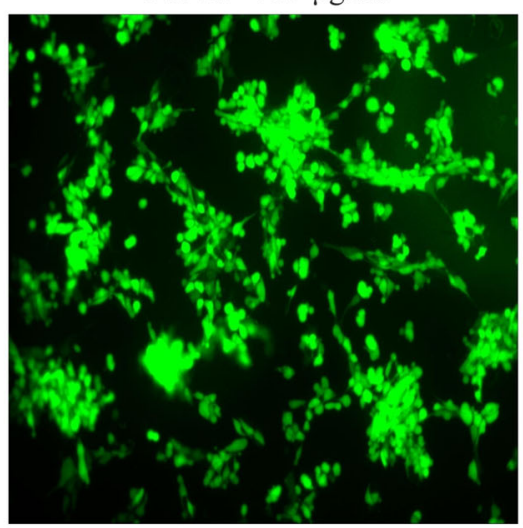

CM $50 \mu \mathrm{g} / \mathrm{ml}$

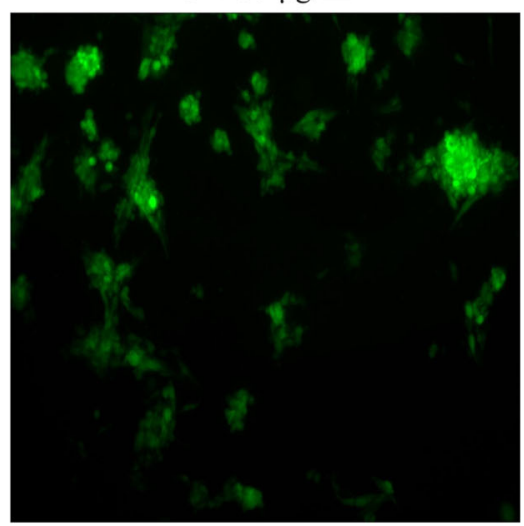

TBHP

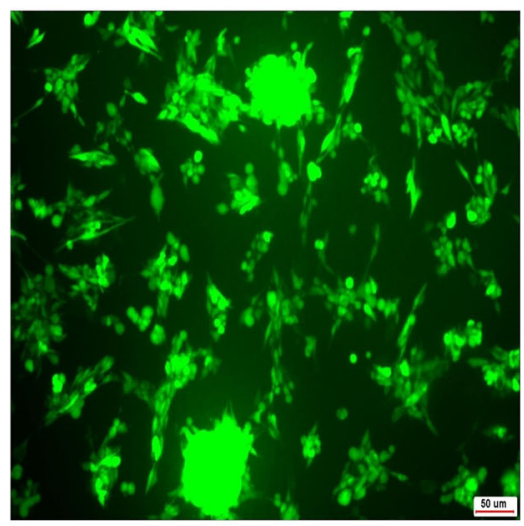

b

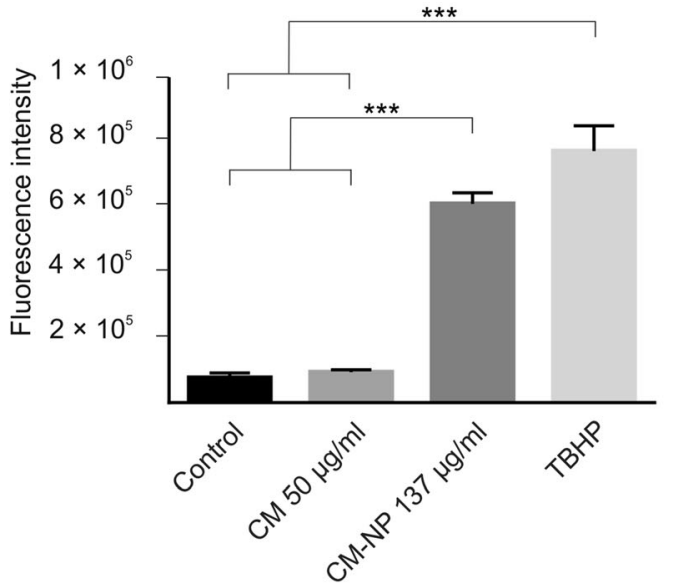

were treated with different values of curcumin (50 and $200 \mu \mathrm{g} / \mathrm{ml}$ ) and CM-NP (137 and $411 \mu \mathrm{g} / \mathrm{ml})$. As indicated in Fig. 12a, treatment of GSCs with curcumin and CM-NP did not affect the secretion of MMP-9. In contrast, the secretion of MMP-2 was significantly reduced by application of curcumin at $200 \mu \mathrm{g} / \mathrm{ml}$ as well as by CM-NP at $411 \mu \mathrm{g} / \mathrm{ml}(P<0.001)$.

\section{CM-NP Inhibits GSCs Invasiveness}

The effects of curcumin and CM-NP on the expression of CXCL3, a tumor metastatic marker, in GSCs were studied.
As shown in Fig. 12b, application of CM-NP did not change the expression level of CXCL3 compared with the control group (Fig. 12b). However, curcumin significantly increased the mRNA expression level of CXCL3 compared with the control group $(P<0.001)$. Furthermore, the effects of curcumin and CM-NP on the expression of MCP1, a key regulator of cell migration and invasion in different cancer types, in GSCs were analyzed. Curcumin significantly increased the expression of MCP1 compared with the control group $(P<0.001)$. However, the expression of MCP1 significantly decreased after CM-NP treatment compared with the 
curcumin-treated cells $(P<0.001)$ and the control group $(P<$ $0.05)$.

\section{CM-NP Changes the Characteristics of GSCs}

\section{CM-NP Disrupts Colony Forming}

To evaluate the self-renewal ability of GSCs, the effects of curcumin $(50 \mu \mathrm{g} / \mathrm{ml})$ and CM-NP $(137 \mu \mathrm{g} / \mathrm{ml})$ on the sphere formation of GSCs seeded in soft agar were assessed for 5 days. A greater damage to the clonal sphere formation was observed after the administration of CM-NP on GSCs compared with the application of curcumin. In addition, a significant decrease in the diameter of tumorspheres was observed 3 days after the application of CM-NP (Fig. 13; $P<0.05$ ).

\section{CM-NP Decreases Cancer Stem Cell Markers}

The expression values of Sox 2 and nestin, the GSCs markers [44], were investigated after the treatment of GSCs with curcumin and CM-NP. Our results demonstrated that the expression of Sox 2 and nestin significantly decreased in GSCs following application of curcumin $(25 \mu \mathrm{g} / \mathrm{ml})$ and CM-NP $(68.5 \mu \mathrm{g} / \mathrm{ml})$ compared with the control group (Fig. 14; $P<0.05$ ). There were no significant differences observed between CM-NP and curcumin effects on the expression of Sox 2 and nestin (Fig. 14).

\section{Discussion}

This in vitro study indicates that the cytotoxic effects of curcumin were markedly enhanced when loaded in niosome nanoparticles. CM-NP, in comparison with curcumin, more effectively reduced the viability, proliferation, and migration of GSCs isolated from human GBM through the induction of cell arrest and apoptosis as well as the enhancement of the expression of Bax, a pro-apoptotic marker. Furthermore, CM-NP considerably inhibited the GSC invasiveness, possibly via the inhibition MCP1, and tumor growth through the upregulation of ROS compared with curcumin. There was no significant difference between the inhibitory effects of curcumin and CM-NP on the expression of nestin and Sox2, neuroepithelial and cancer stem cell markers, in GSCs. Our data indicate that CM-NP, as a potentially safe compound with little effect on normal cells, exerts greater anti-tumor effects compared with free curcumin.

Over the last two decades, nanoparticle-based drug delivery systems have been developed for the treatment of various diseases, including brain tumors [45]. Various types of nanoparticle, including polymer-based, lipid-based, niosomal, viral, inorganic, and drug-conjugated, have been designed to target and demolish cancer cells [46]. Although different nanoparticles of curcumin formulations have been developed to improve its solubility, bioavailability, safety, and efficacy, none of those reaches optimal values [47]. Niosomal drug delivery approach enhances drug potency and reduces drug toxicity through keeping the compound localized at the site of application, increasing the drug stability, and improving drug penetrating capability [48]. In the present study, CM-NP has an average diameter of $\sim 60 \mathrm{~nm}$ with a zeta potential of $\sim-35 \mathrm{mV}$ and $\sim 80 \%$ drug entrapment efficiency, which indicates an efficient encapsulation of curcumin [49]. The physical and chemical properties of CM-NP represent a permeable, stable, and inexpensive component for targeted curcumin delivery to cancer cells [31]. CM-NP exhibits a greater cytotoxic effect on GSCs compared with free curcumin. In keeping with our results, the anti-tumor effect of other types of curcumin nanoparticles, such as nanoliposome, was significantly greater than that of the free curcumin $[26,27$, 50]. Niosome is among the promising drug carriers that act as a pool to release compounds in a steady, controlled, and sustained manner [51]. Inability to deliver active drug substances through the BBB to a large portion of GBM cells prevents efficient passage of drug molecules and contributes to treatment failure [52]. Due to low bioavailability, curcumin is not predicted to cross the BBB efficiently [53]. Engineered niosome encapsulation of curcumin has the potential to enhance the delivery of curcumin into the brain tumor $[32,54]$. Curcumin and CM-NP at the IC50 value after $24 \mathrm{~h}$ (were 50 and $137 \mu \mathrm{g} / \mathrm{ml}$ ) were applied on GSCs to study their anti-tumor effects. However, in the migration assay (wound healing stretch) and immunocytochemistry studies, lower concentrations of curcumin and CMNP were administered to reduce their cytotoxicity for a better evaluation of cell behaviors, particularly when the compounds were used for longer than $24 \mathrm{~h}$. For the evaluation of cell cycle arrest and apoptosis, alongside with IC50 concentrations of the substances, higher values were also tested. Our data suggest CM-NP at the IC50 value $(137 \mu \mathrm{g} / \mathrm{ml})$ as the optimal concentration for future studies.

GSCs are suggested to be responsible for tumor occurrence and progression as well as chemo- and radiation-therapy resistance [2]. In line with our data, several studies have shown that different curcuminoids, such as free curcumin [55], hydrazinobenzoylcurcumin [56], and demethoxycurcumin [20], exert cytotoxic effects on GSCs. In addition, application of liposomal or phytosomal curcumin inhibits the growth of GSCs $[57,58]$. The present data indicate a greater effect of CM-NP on GSCs viability and proliferation compared with free curcumin. The greater inhibitory effects of CM-NP on GSCs proliferation could be due to a strong cell cycle arrest together with an effective apoptotic effect. It has been reported that curcumin can suppress GSCs and GBM growth via the inhibition of cell proliferation and survival, as well as regulation of diverse anti-tumor signaling pathways, including activation of apoptotic pathways, disruption of molecular 
a
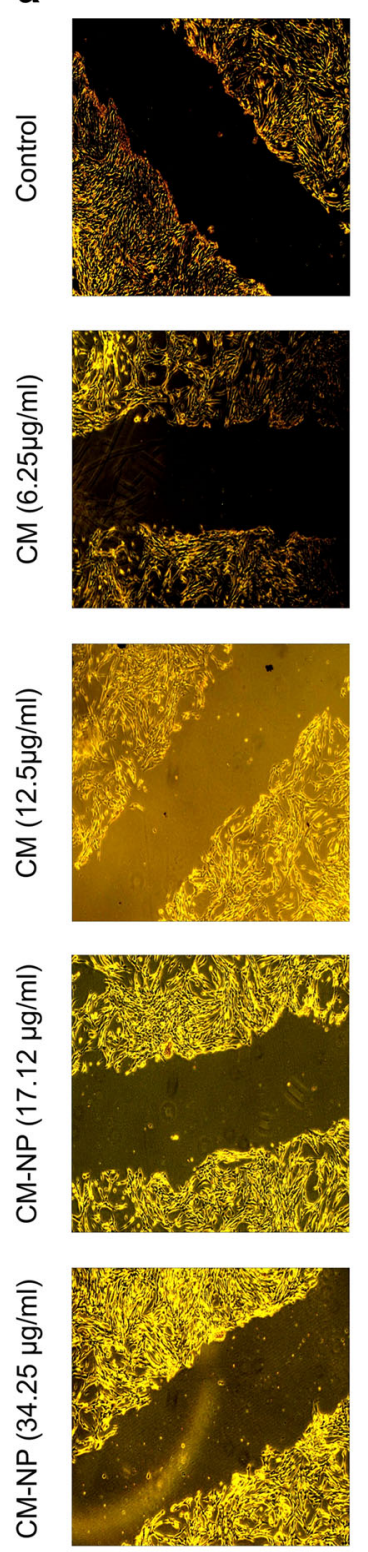

b

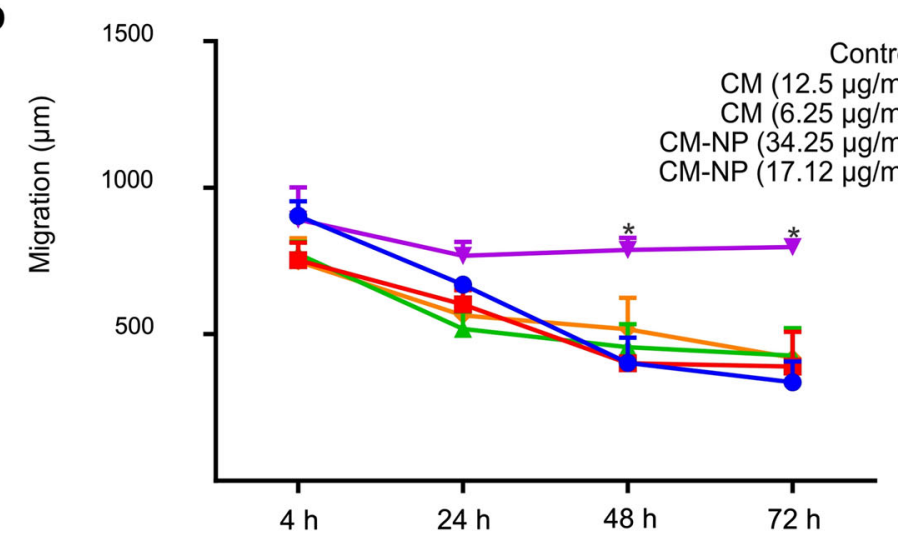

Control $\rightarrow-$

$\mathrm{CM}(12.5 \mu \mathrm{g} / \mathrm{ml}) \longrightarrow$ $5 \mu \mathrm{g} / \mathrm{ml}) \longrightarrow$ M-NP $(34.25 \mu \mathrm{g} / \mathrm{ml}) \rightarrow$

$4 \mathrm{~h}-24 \mathrm{~h}$
$72 \mathrm{~h}$
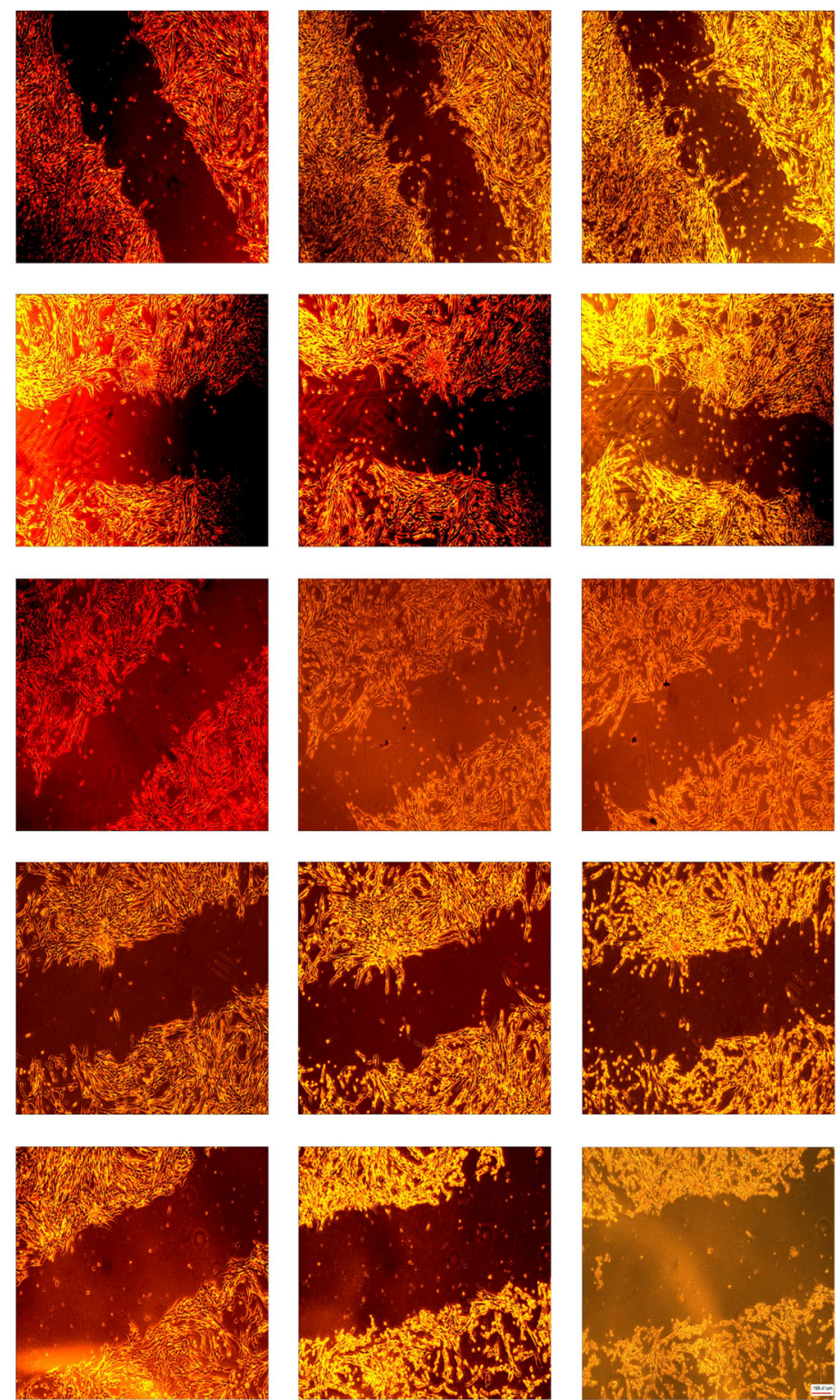

signaling, inhibition of cell cycle, inhibition of angiogenesis, increase in ROS, recruitment of natural killer cells, enhancement of autophagy, and induction of differentiation of glioma-initiating cells $[59,60]$. 
Fig. 11 The effects of curcumin (CM) and curcumin-encapsulated noisome nanoparticle (CM-NP) on the migration of glioblastoma stem-like cells (GSCs). a Migration of GSCs was assessed by the wound healing method. After GSCs have reached $90 \%$ confluence, a scratch wound across a confluent monolayer of cultured cells was created on the cell surface using a micropipette tip and then CM $(6.25$ and $12.5 \mu \mathrm{g} / \mathrm{ml})$ and CM-NP (17.12 and $34.25 \mu \mathrm{g} / \mathrm{ml})$ were added. The cultures were incubated at $37^{\circ} \mathrm{C}$ and images were captured with a microscope at $4,24,48$, and $72 \mathrm{~h}$ of treatments. $\mathbf{b}$ The cell migration rate was estimated by the measurement of cell numbers within the wound region. CM-NP at $34.25 \mu \mathrm{g} / \mathrm{ml}$ significantly inhibited the migration of GSCs after $48 \mathrm{~h}$ and $72 \mathrm{~h}$ of application compared with the CM and control groups. The data are presented as mean $\pm \mathrm{SD}$. The asterisk indicates $P<0.05$

Treatment of GSCs with both curcumin and CM-NP modulates signaling pathway of apoptosis via enhancement of Bax and reduction of Bcl2. In contrast to CM-NP, curcumin also regulates $\mathrm{p} 53$ pathway. The tumor suppressor protein $\mathrm{p} 53$ is crucial in GBM prevention via modulating of a broad range of cellular responses, such as apoptosis of injured cells, reduction of angiogenesis, enhancement of genomic stability, regulation of cell cycle, and modulation of cell metabolism and tumor micromilieu [61]. Disruption of P53 pathway, presented in more than $90 \%$ of patients with GBM, is accompanied with a worse prognosis and is a crucial target for treatment approaches [62]. Previous investigations indicate that curcumin can cause apoptosis in both p53-dependent and p53independent manners $[63,64]$. Curcumin can promote the induction of apoptosis independently of $\mathrm{p} 53$ via phosphorylation of ROS, downregulation of anti-apoptotic protein Bcl-2, and enhancement of superoxide anion production [65]. The $\mathrm{Bcl}-2$ expression has been reported in more than half of patients with GBM and Bcl-2 overexpression significantly enhanced tumor resistance against cytotoxic agents [66]. In addition, Bax activation inhibits proliferation and induces apoptosis of human GSCs [67]. In agreement with our findings, free curcumin increased Bax-Bcl-2 ratio and suppressed human GBM cell viability [68]. On the other hand, elevated NFB activity and cytokine IL-6 release is correlated with cell viability in different GBM cell lines and with poor prognosis in patients with GBM [18]. NF- B plays a key role in both apoptotic and necrotic programmed cell death [69]. Inhibition of NF- B induces mitochondrial dysfunction with cell cycle arrest in the G2/M phase [18]. The present data support previous studies $[68,70]$ which indicate that the greater cytotoxic effect of CM-NP on GSCs compared with curcumin may exert
Fig. 12 The effects of curcumin (CM) and curcumin-encapsulated noisome nanoparticle (CM-NP) on invasiveness of glioblastoma stem-like cells (GSCs). a

Gelatinase zymogram and densitometry analysis of MMP-9 (left) and MMP-2 (right) secretion in conditioned media were detected by electrophoresis of soluble protein on a gelatin containing $10 \%$ polyacrylamide gel. Areas and relative intensities of gelatindigested bands by MMP- 9 and MMP-2 were quantified by densitometry and expressed as relative MMP-9 and MMP-2 activity compared with that of untreated cells. b The mRNA expression of CXCL3 and MCP-1 in GSCs treated with $\mathrm{CM}$ and CM-NP. Histogram represents mean $\pm \mathrm{SD}$. Triple asterisks indicate $P<0.001$

\section{a}
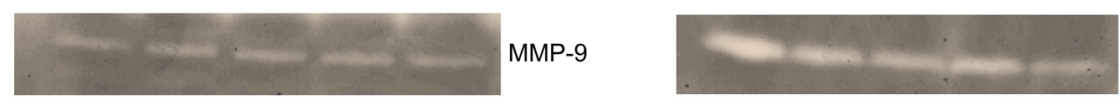
MMP-2
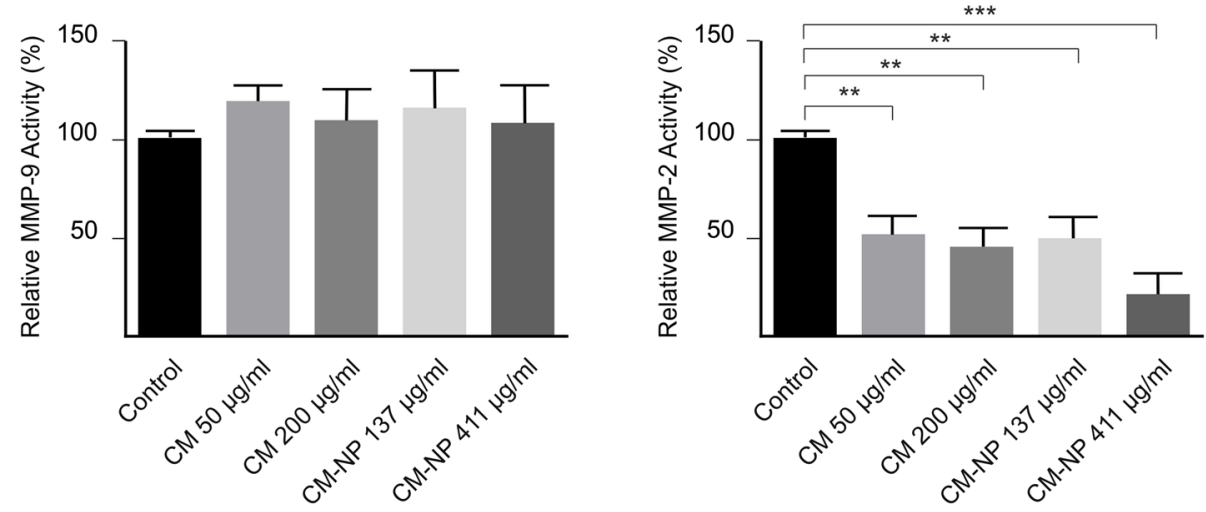

b

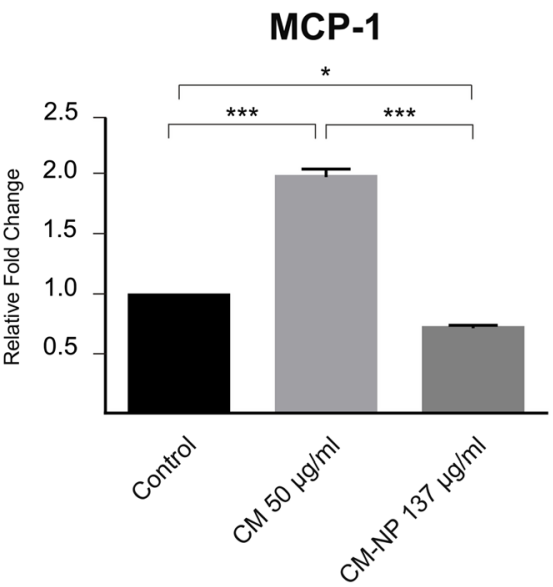




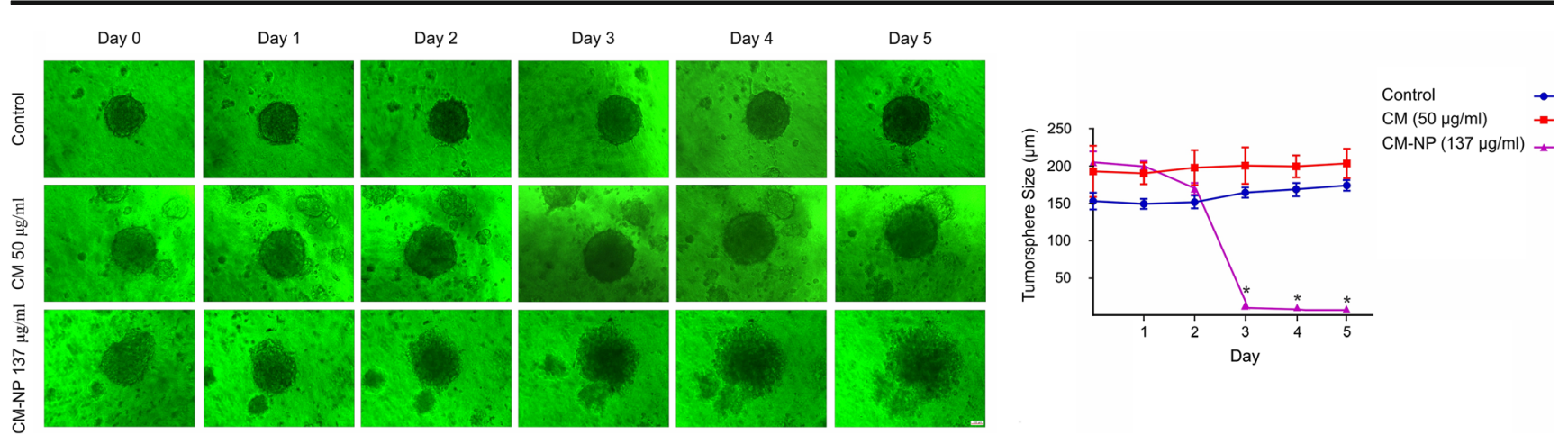

Fig. 13 The effects of curcumin (CM) and curcumin-encapsulated noisome nanoparticle (CM-NP) on colony formation of glioblastoma stemlike cells (GSCs). The colony formation of GSCs was assessed in soft agar treated with CM $(50 \mu \mathrm{g} / \mathrm{ml})$ and CM-NP $(137 \mu \mathrm{g} / \mathrm{ml})$ for 5 days.

through inhibition of the activation of NF- $\mathrm{kB}$ activity and the release of IL-6.

Reduced value of ROS is involved in the multistep oncogenesis process of GBM via the promoting of cell proliferation and survival as well as the activation of NF-KB. Enhanced ROS generation exerts anti-cancer effects via the induction of cell cycle arrest and apoptosis [71]. CM-NP exerts a significant higher effect on the production of ROD compared with curcumin. In agreement with a previous study, our data suggested that CM-NP may target GSC viability through the enhancement of ROS [55]. MMP-2 and MMP-9 play a crucial role in glioma invasiveness [72]. CM-NP suppressed the MMP-2 enzymatic activity, whereas it did not affect the
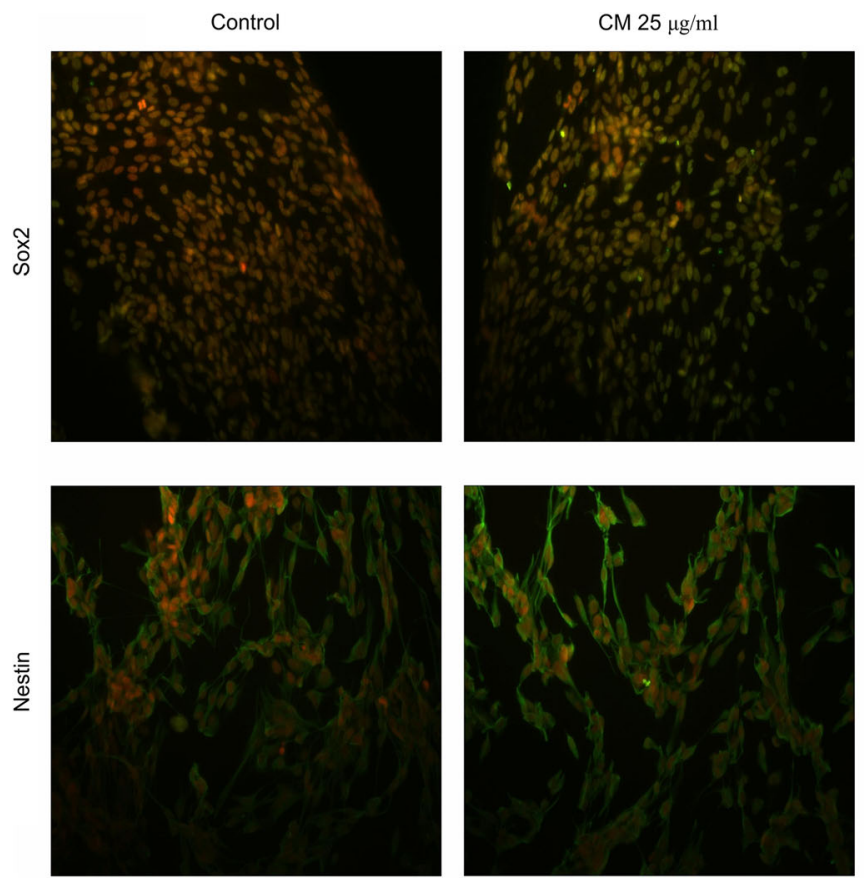

Fig. 14 The effects of curcumin (CM) and curcumin-encapsulated noisome nanoparticle (CM-NP) on the expression of Sox2 and nestin in glioblastoma stem-like cells (GSCs). Quantitative analysis of the expression of Sox 2 and nestin in GSCs revealed a significant reduction of these
CM-NP significantly decreased the size of tumor sphere and inhibited colony formation of GSCs. The data are presented as mean \pm SD. The asterisk indicates $P<0.05$

MMP-9 activity in GSCs. Contrary to these findings, previous studies have suggested that curcumin is able to suppress the secretion of MMP-9 in GBM cell lines [15, 16]. In addition to MMP, chemokines play multiple roles in GBM invasion, proliferation, migration, and angiogenesis [73]. CXCL3 could bind to the chemokine receptor CXCR2 and regulates the progression and metastasis of malignant tumor [74, 75]. Evidence suggests that CXCL3 promotes the invasiveness of cancerous cells and may be a potential target for cancer therapy [74]. However, little is known about its function in glioblastoma [76]. Our study revealed that CM-NP could not inhibit CXCL3 in GSCs compared with the control group. However, CM-NP inhibited significantly the expression of
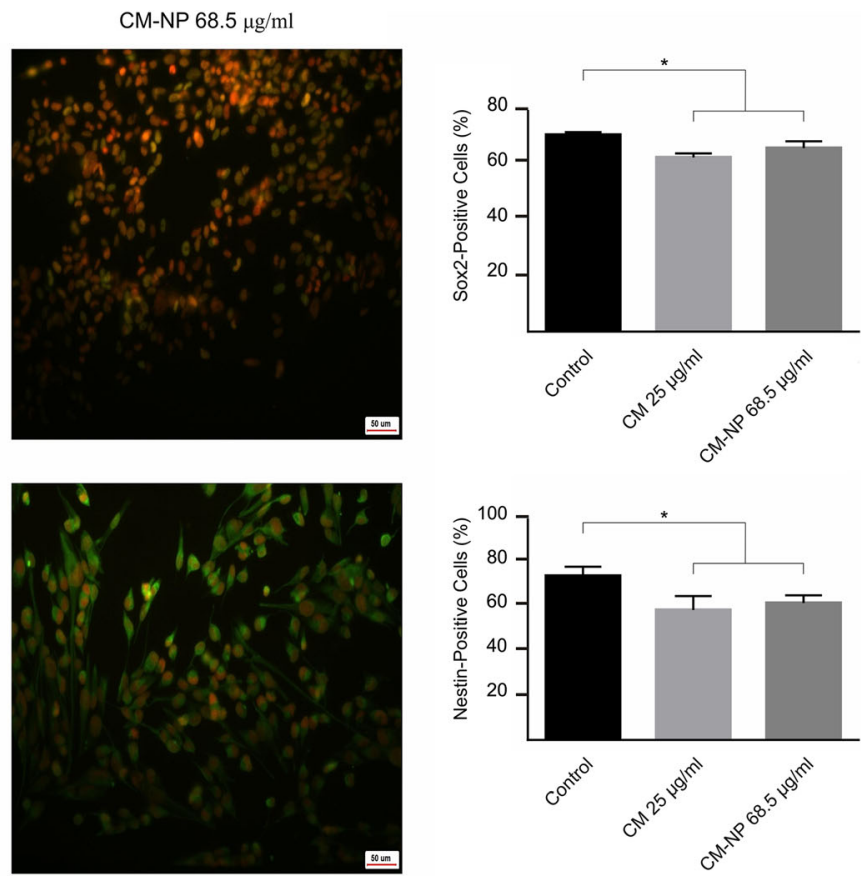

two markers after treatment with CM and CM-NP. Cells were stained for markers are shown in green and nuclei were stained with propidium iodide are shown in red. The data are expressed as mean $\pm \mathrm{SD}$. The asterisk indicates $P<0.05$ 
MCP1 in GSCs compared with free curcumin. Interestingly, CCL2/MCP-1 (as the top-listed NF- $K B$-regulated gene) stimulated migration and invasion of GBM cells in a paracrine mode [76].

GSCs express both embryonic and neural progenitor cancer stem cell markers, including SOX2, nestin, and CD133. However, it should be noted that the expression of these markers is not restricted to one particular cell type in GBM [77]. A previous investigation has shown that a polymeric nanoparticle formulation of curcumin significantly inhibited clonogenic growth and decreased the number of CD133positive stem-like population of GBM cells [28]. Here, both CM-NP and free curcumin significantly decreased the percentage of Sox2- and nestin-positive cells in GSCs. This may suggest the importance of these markers to identify GSCs and to explore the novel therapeutic approaches of GBM.

\section{Conclusion}

The present study is the first to investigate the effect of a novel nano-niosome-loaded curcumin on GSCs. CM-NP was appropriately designed for the delivery of curcumin to GBM stem cells and the anti-tumor properties of curcumin significantly promoted when loaded in niosome nanoparticles. Our findings revealed that CM-NP more efficiently targets the viability, proliferation, and migration of GSCs than curcumin through multiple molecular mechanisms, including induction of cell cycle arrest, apoptosis, and ROS generation. CM-NP also alleviates GSC invasiveness via regulation of MCP-1. Our data suggested that nano-niosome could be used as an ideal carrier to deliver curcumin for possible therapeutic approaches of GBM. However, these findings should be interpreted with caution. Further in vivo investigations are warranted to confirm the anti-tumor effect of CM-NP on GBM and to validate their probable use in clinical trials.

Author Contributions SSN, FA, MJN, and ARA performed experiments as well as collected and analyzed data. SS and GR designed and produced curcumin nanoparticle. FS provided tumor tissues. SSN, FS, GR, and AG contributed to experimental design and its implementation. SSN and AG contributed to the interpretation of the data and wrote preliminary draft of the manuscript. All authors read and approved the final version of the manuscript.

Funding Information Open access funding provided by Projekt DEAL. This study was financially supported by the Iran National Science Foundation (INSF), National Institute for Medical Research (NIMAD; 964650), and the German Academic Exchange Service (DAAD; 57348208 and 57403633) to AG.

\section{Compliance with Ethical Standards}

Informed consent was obtained from the patient. The experimental protocol was evaluated and approved by the Ethical Committee of Shefa Neuroscience Research Center, Tehran, Iran.
Conflict of interest The authors declare that they have no conflict of interest.

Open Access This article is licensed under a Creative Commons Attribution 4.0 International License, which permits use, sharing, adaptation, distribution and reproduction in any medium or format, as long as you give appropriate credit to the original author(s) and the source, provide a link to the Creative Commons licence, and indicate if changes were made. The images or other third party material in this article are included in the article's Creative Commons licence, unless indicated otherwise in a credit line to the material. If material is not included in the article's Creative Commons licence and your intended use is not permitted by statutory regulation or exceeds the permitted use, you will need to obtain permission directly from the copyright holder. To view a copy of this licence, visit http://creativecommons.org/licenses/by/4.0/.

\section{References}

1. Louis DN, Ohgaki H, Wiestler OD (2007) WHO classification of tumours of the central nervous system, vol 1. WHO Regional Office Europe

2. Lathia JD, Mack SC, Mulkearns-Hubert EE, Valentim CL, Rich JN (2015) Cancer stem cells in glioblastoma. Genes Dev 29(12):12031217

3. Sattiraju A, Sai KKS, Mintz A (2017) Glioblastoma stem cells and their microenvironment. In: Stem cell microenvironments and beyond. Springer, pp. 119-140

4. Kahlert UD, Mooney SM, Natsumeda M, Steiger HJ, Maciaczyk J (2017) Targeting cancer stem-like cells in glioblastoma and colorectal cancer through metabolic pathways. Int J Cancer 140(1):10 22. https://doi.org/10.1002/ijc.30259

5. Sordillo LA, Sordillo PP, Helson L (2015) Curcumin for the treatment of glioblastoma. Anticancer Res 35(12):6373-6378

6. Lee WH, Loo CY, Young PM, Traini D, Mason RS, Rohanizadeh R (2014) Recent advances in curcumin nanoformulation for cancer therapy. Expert Opin Drug Deliv 11(8):1183-1201. https://doi.org/ 10.1517/17425247.2014.916686

7. Aggarwal BB, Kumar A, Bharti AC (2003) Anticancer potential of curcumin: Preclinical and clinical studies. Anticancer Res 23(1/A): 363-398

8. Agrawal DK, Mishra PK (2010) Curcumin and its analogues: potential anticancer agents. Med Res Rev 30(5):818-860

9. Hatcher H, Planalp R, Cho J, Torti FM, Torti SV (2008) Curcumin: from ancient medicine to current clinical trials. Cell Mol Life Sci 65(11):1631-1652. https://doi.org/10.1007/s00018-008-7452-4

10. Ravindran J, Prasad S, Aggarwal BB (2009) Curcumin and cancer cells: how many ways can curry kill tumor cells selectively? AAPS J 11(3):495-510

11. Wu B, Yao H, Wang S, Xu R (2013) DAPK1 modulates a curcumin-induced $\mathrm{G} 2 / \mathrm{M}$ arrest and apoptosis by regulating STAT3, NF-KB, and caspase-3 activation. Biochem Biophys Res Commun 434(1):75-80

12. Guo YQJMX, Cao JSYYB, Zhang L (2015) Curcumin enhances the radiosensitivity of U87 cells by inducing DUSP-2 up-regulation. Cell Physiol Biochem 35:1381-1393

13. Pauwels B, Wouters A, Peeters M, Vermorken JB, Lardon F (2010) Role of cell cycle perturbations in the combination therapy of chemotherapeutic agents and radiation. Future Oncol 6(9):1485-1496. https://doi.org/10.2217/fon.10.104

14. Senft C, Polacin M, Priester M, Seifert V, Kogel D, Weissenberger J (2010) The nontoxic natural compound Curcumin exerts antiproliferative, anti-migratory, and anti-invasive properties against 
malignant gliomas. BMC Cancer 10:491. https://doi.org/10.1186/ 1471-2407-10-491

15. Woo MS, Jung SH, Kim SY, Hyun JW, Ko KH, Kim WK, Kim HS (2005) Curcumin suppresses phorbol ester-induced matrix metalloproteinase-9 expression by inhibiting the PKC to MAPK signaling pathways in human astroglioma cells. Biochem Biophys Res Commun 335(4):1017-1025. https://doi.org/10.1016/j.bbrc. 2005.07.174

16. Kim S-Y, Jung S-H, Kim H-S (2005) Curcumin is a potent broad spectrum inhibitor of matrix metalloproteinase gene expression in human astroglioma cells. Biochem Biophys Res Commun 337(2): $510-516$

17. Thani A, Azela N, Sallis B, Nuttall R, Schubert FR, Ahsan M, Davies D, Purewal S et al (2012) Induction of apoptosis and reduction of MMP gene expression in the U373 cell line by polyphenolics in Aronia melanocarpa and by curcumin. Oncol Rep 28(4): $1435-1442$

18. Zanotto-Filho A, Braganhol E, Schröder R, de Souza LHT, Dalmolin RJ, Pasquali MAB, Gelain DP, Battastini AMO et al (2011) NFKB inhibitors induce cell death in glioblastomas. Biochem Pharmacol 81(3):412-424

19. Dhandapani KM, Mahesh VB, Brann DW (2007) Curcumin suppresses growth and chemoresistance of human glioblastoma cells via AP-1 and NFKB transcription factors. J Neurochem 102(2): $522-538$

20. Leng L, Zhong X, Sun G, Qiu W, Shi L (2016) Demethoxycurcumin was superior to temozolomide in the inhibition of the growth of glioblastoma stem cells in vivo. Tumour Biol 37:15847-15857. https://doi.org/10.1007/s13277-016-5399-x

21. Tsai Y-M, Chien C-F, Lin L-C, Tsai T-H (2011) Curcumin and its nano-formulation: the kinetics of tissue distribution and bloodbrain barrier penetration. Int J Pharm 416(1):331-338

22. Ganta S, Amiji M (2009) Coadministration of paclitaxel and curcumin in nanoemulsion formulations to overcome multidrug resistance in tumor cells. Mol Pharm 6(3):928-939. https://doi. org $/ 10.1021 / \mathrm{mp} 800240 \mathrm{j}$

23. Nair KL, Thulasidasan AK, Deepa G, Anto RJ, Kumar GS (2012) Purely aqueous PLGA nanoparticulate formulations of curcumin exhibit enhanced anticancer activity with dependence on the combination of the carrier. Int J Pharm 425(1-2):44-52. https://doi.org/ 10.1016/j.ijpharm.2012.01.003

24. Mohanty C, Sahoo SK (2010) The in vitro stability and in vivo pharmacokinetics of curcumin prepared as an aqueous nanoparticulate formulation. Biomaterials 31(25):6597-6611. https://doi.org/10.1016/j.biomaterials.2010.04.062

25. Ma Z, Haddadi A, Molavi O, Lavasanifar A, Lai R, Samuel J (2008) Micelles of poly(ethylene oxide)-b-poly(epsiloncaprolactone) as vehicles for the solubilization, stabilization, and controlled delivery of curcumin. J Biomed Mater Res A 86(2): 300-310. https://doi.org/10.1002/jbm.a.31584

26. Bisht S, Feldmann G, Soni S, Ravi R, Karikar C, Maitra A, Maitra A (2007) Polymeric nanoparticle-encapsulated curcumin ("nanocurcumin"): a novel strategy for human cancer therapy. J Nanobiotechnol 5:3. https://doi.org/10.1186/1477-3155-5-3

27. Zhao M, Zhao M, Fu C, Yu Y, Fu A (2018) Targeted therapy of intracranial glioma model mice with curcumin nanoliposomes. Int $\mathrm{J}$ Nanomedicine 13:1601-1610. https://doi.org/10.2147/IJN. S157019

28. Lim KJ, Bisht S, Bar EE, Maitra A, Eberhart CG (2011) A polymeric nanoparticle formulation of curcumin inhibits growth, clonogenicity and stem-like fraction in malignant brain tumors. Cancer Biol Ther 11(5):464 473. https://doi.org/10.4161/cbt.11.5. 14410

29. Lim KJ, Maitra A, Bisht S, Eberhart C, Bar E (2010) Using nanocurcumin to treat medulloblastoma and glioblastoma. AACR
30. Srinivas S, Kumar YA, Hemanth A, Anitha M (2010) Preparation and evaluation of niosomes containing aceclofenac. Dig J Nanomater Bios 5(1):249-254

31. Bartelds R, Nematollahi MH, Pols T, Stuart MCA, Pardakhty A, Asadikaram G, Poolman B (2018) Niosomes, an alternative for liposomal delivery. PLoS One 13(4):e0194179. https://doi.org/10. 1371/journal.pone.0194179

32. Gharbavi M, Amani J, Kheiri-Manjili H, Danafar H, Sharafi A (2018) Niosome: a promising nanocarrier for natural drug delivery through blood-brain barrier. Adv Pharmacol Sci 2018:68479716847915. https://doi.org/10.1155/2018/6847971

33. Basiri L, Rajabzadeh G, Bostan A (2017) Physicochemical properties and release behavior of Span 60/Tween 60 niosomes as vehicle for $\alpha$-Tocopherol delivery. LWT 84:471-478

34. Sharma V, Anandhakumar S, Sasidharan M (2015) Self-degrading niosomes for encapsulation of hydrophilic and hydrophobic drugs: an efficient carrier for cancer multi-drug delivery. Mater Sci Eng C Mater Biol Appl 56:393-400. https://doi.org/10.1016/j.msec.2015. 06.049

35. Anitha A, Deepagan V, Rani VD, Menon D, Nair S, Jayakumar R (2011) Preparation, characterization, in vitro drug release and biological studies of curcumin loaded dextran sulphate-chitosan nanoparticles. Carbohydr Polym 84(3):1158-1164

36. Liao Z-X, Li Y-C, Lu H-M, Sung H-W (2014) A geneticallyencoded KillerRed protein as an intrinsically generated photosensitizer for photodynamic therapy. Biomaterials 35(1):500-508

37. Garbisa S, Sartor L, Biggin S, Salvato B, Benelli R, Albini A (2001) Tumor gelatinases and invasion inhibited by the green tea flavanol epigallocatechin-3-gallate. Cancer 91(4):822-832

38. Wang X, Deng J, Yuan J, Tang X, Wang Y, Chen H, Liu Y, Zhou L (2017) Curcumin exerts its tumor suppressive function via inhibition of NEDD4 oncoprotein in glioma cancer cells. Int J Oncol 51(2):467-477. https://doi.org/10.3892/ijo.2017.4037

39. Negah SS, Khaksar Z, Aligholi H, Sadeghi SM, Mousavi SMM, Kazemi H, Jahan-Abad AJ, Gorji A (2017) Enhancement of neural stem cell survival, proliferation, migration, and differentiation in a novel self-assembly peptide nanofibber scaffold. Mol Neurobiol 54(10):8050-8062

40. Chen $\mathrm{J}$ (2016) The cell-cycle arrest and apoptotic functions of $\mathrm{p} 53$ in tumor initiation and progression. Cold Spring Harb Perspect Med 6(3):a026104. https://doi.org/10.1101/cshperspect.a026104

41. Xia Y, Shen S, Verma IM (2014) NF-kappaB, an active player in human cancers. Cancer Immunol Res 2(9):823-830. https://doi.org/ 10.1158/2326-6066.CIR-14-0112

42. Larasati YA, Yoneda-Kato N, Nakamae I, Yokoyama T, Meiyanto E, Kato JY (2018) Curcumin targets multiple enzymes involved in the ROS metabolic pathway to suppress tumor cell growth. Sci Rep 8(1):2039. https://doi.org/10.1038/s41598-018-20179-6

43. Du R, Petritsch C, Lu K, Liu P, Haller A, Ganss R, Song H, Vandenberg $S$ et al (2008) Matrix metalloproteinase-2 regulates vascular patterning and growth affecting tumor cell survival and invasion in GBM. Neuro-oncology 10(3):254-264. https://doi. org/10.1215/15228517-2008-001

44. Iacopino F, Angelucci C, Piacentini R, Biamonte F, Mangiola A, Maira G, Grassi C, Sica G (2014) Isolation of cancer stem cells from three human glioblastoma cell lines: characterization of two selected clones. PLoS One 9(8):e105166. https://doi.org/10.1371/ journal.pone. 0105166

45. Wang H, Agarwal P, Zhao S, Yu J, Lu X, He X (2016) Combined cancer therapy with hyaluronan-decorated fullerene-silica multifunctional nanoparticles to target cancer stem-like cells. Biomaterials 97:62-73

46. Tran S, DeGiovanni PJ, Piel B, Rai P (2017) Cancer nanomedicine: a review of recent success in drug delivery. Clin Transl Med 6(1): 44. https://doi.org/10.1186/s40169-017-0175-0 
47. Maiti P, Scott J, Sengupta D, Al-Gharaibeh A, Dunbar GL (2019) Curcumin and solid lipid curcumin particles induce autophagy, but inhibit mitophagy and the PI3K-Akt/mTOR pathway in cultured glioblastoma cells. Int J Mol Sci 20(2). https://doi.org/10.3390/ ijms20020399

48. Kazi KM, Mandal AS, Biswas N, Guha A, Chatterjee S, Behera M, Kuotsu K (2010) Niosome: a future of targeted drug delivery systems. J Adv Pharm Technol Res 1(4):374-380. https://doi.org/10. 4103/0110-5558.76435

49. Okore VC, Attama AA, Ofokansi KC, Esimone CO, Onuigbo EB (2011) Formulation and evaluation of niosomes. Indian J Pharm Sci 73(3):323-328. https://doi.org/10.4103/0250-474X.93515

50. Langone $P$, Debata PR, Inigo Jdel R, Dolai S, Mukherjee S, Halat $P$, Mastroianni K, Curcio GM et al (2014) Coupling to a glioblastomadirected antibody potentiates antitumor activity of curcumin. Int $\mathrm{J}$ Cancer 135(3):710-719. https://doi.org/10.1002/ijc.28555

51. Gharbavi M, Amani J (2018) Niosome: a promising nanocarrier for natural drug delivery through blood-brain barrier. 2018:68479716847915. https://doi.org/10.1155/2018/6847971

52. van Tellingen $\mathrm{O}$, Yetkin-Arik $\mathrm{B}$, de Gooijer MC, Wesseling $\mathrm{P}$, Wurdinger T, de Vries HE (2015) Overcoming the blood-brain tumor barrier for effective glioblastoma treatment. Drug Resist Updat 19:1-12. https://doi.org/10.1016/j.drup.2015.02.002

53. Zanotto-Filho A, Coradini K, Braganhol E, Schroder R, de Oliveira CM, Simoes-Pires A, Battastini AM, Pohlmann AR et al (2013) Curcumin-loaded lipid-core nanocapsules as a strategy to improve pharmacological efficacy of curcumin in glioma treatment. Eur $\mathrm{J}$ Pharm Biopharm 83(2):156-167. https://doi.org/10.1016/j.ejpb. 2012.10.019

54. Bragagni M, Mennini N, Furlanetto S, Orlandini S, Ghelardini C, Mura P (2014) Development and characterization of functionalized niosomes for brain targeting of dynorphin-B. Eur J Pharm Biopharm 87(1):73-79. https://doi.org/10.1016/j.ejpb.2014.01.006

55. Gersey ZC, Rodriguez GA, Barbarite E, Sanchez A, Walters WM, Ohaeto KC, Komotar RJ, Graham RM (2017) Curcumin decreases malignant characteristics of glioblastoma stem cells via induction of reactive oxygen species. BMC Cancer 17(1):99. https://doi.org/10. 1186/s12885-017-3058-2

56. Shin HJ, Lee S, Jung HJ (2019) A curcumin derivative hydrazinobenzoylcurcumin suppresses stem-like features of glioblastoma cells by targeting $\mathrm{Ca}(2+)$ /calmodulin-dependent protein kinase II. J Cell Biochem 120(4):6741-6752. https://doi.org/10. 1002/jcb.27972

57. Wang Y, Ying X, Xu H, Yan H, Li X, Tang H (2017) The functional curcumin liposomes induce apoptosis in C6 glioblastoma cells and C6 glioblastoma stem cells in vitro and in animals. Int $\mathrm{J}$ Nanomedicine 12:1369-1384. https://doi.org/10.2147/IJN.S124276

58. Mukherjee S, Fried A, Hussaini R, White R, Baidoo J, Yalamanchi S, Banerjee P (2018) Phytosomal curcumin causes natural killer cell-dependent repolarization of glioblastoma (GBM) tumorassociated microglia/macrophages and elimination of GBM and GBM stem cells. J Exp Clin Cancer Res 37(1):168. https://doi. org/10.1186/s13046-018-0792-5

59. Fong D, Yeh A, Naftalovich R, Choi TH, Chan MM (2010) Curcumin inhibits the side population (SP) phenotype of the rat C6 glioma cell line: towards targeting of cancer stem cells with phytochemicals. Cancer Lett 293(1):65-72. https://doi.org/10. 1016/j.canlet.2009.12.018

60. Zhuang W, Long L, Zheng B, Ji W, Yang N, Zhang Q, Liang Z (2012) Curcumin promotes differentiation of glioma-initiating cells by inducing autophagy. Cancer Sci 103(4):684-690

61. Zhang Y, Dube C, Gibert M Jr, Cruickshanks N, Wang B, Coughlan M, Yang Y, Setiady I et al (2018) The p53 pathway in glioblastoma. Cancers 10(9). https://doi.org/10.3390/cancers10090297

62. Touat M, Idbaih A, Sanson M, Ligon KL (2017) Glioblastoma targeted therapy: updated approaches from recent biological insights. Ann Oncol 28(7):1457-1472. https://doi.org/10.1093/ annonc/mdx 106

63. Shankar S, Srivastava RK (2007) Involvement of Bcl-2 family members, phosphatidylinositol 3'-kinase/AKT and mitochondrial p53 in curcumin (diferulolylmethane)-induced apoptosis in prostate cancer. Int J Oncol 30(4):905-918

64. Talib WH, Al-Hadid SA, Ali MBW, Al-Yasari IH, Ali MRA (2018) Role of curcumin in regulating p53 in breast cancer: an overview of the mechanism of action. Breast Cancer (Dove Medical Press) 10: 207-217. https://doi.org/10.2147/BCTT.S167812

65. Watson JL, Hill R, Yaffe PB, Greenshields A, Walsh M, Lee PW, Giacomantonio CA, Hoskin DW (2010) Curcumin causes superoxide anion production and $\mathrm{p} 53$-independent apoptosis in human colon cancer cells. Cancer Lett 297(1):1-8. https://doi.org/10.1016/j. canlet.2010.04.018

66. Fels C, Schafer C, Huppe B, Bahn H, Heidecke V, Kramm CM, Lautenschlager C, Rainov NG (2000) Bcl-2 expression in highergrade human glioma: a clinical and experimental study. J NeuroOncol 48(3):207-216

67. Cartron PF, Oliver L, Martin S, Moreau C, LeCabellec MT, Jezequel P, Meflah K, Vallette FM (2002) The expression of a new variant of the pro-apoptotic molecule Bax, Baxpsi, is correlated with an increased survival of glioblastoma multiforme patients. Hum Mol Genet 11(6):675-687. https://doi.org/10.1093/hmg/11.6.675

68. Karmakar S, Banik NL, Ray SK (2007) Curcumin suppressed antiapoptotic signals and activated cysteine proteases for apoptosis in human malignant glioblastoma U87MG cells. Neurochem Res 32(12):2103-2113. https://doi.org/10.1007/s11064-007-9376-Z

69. Fan Y, Dutta J, Gupta N, Fan G, Gelinas C (2008) Regulation of programmed cell death by NF-kappaB and its role in tumorigenesis and therapy. Adv Exp Med Biol 615:223-250. https://doi.org/10. 1007/978-1-4020-6554-5_11

70. Zhao J, Zhu J, Lv X, Xing J, Liu S, Chen C, Xu Y (2017) Curcumin potentiates the potent antitumor activity of ACNU against glioblastoma by suppressing the PI3K/AKT and NF-kappaB/COX-2 signaling pathways. OncoTargets Ther 10:5471-5482. https://doi.org/ 10.2147/OTT.S149708

71. Rinaldi M, Caffo M, Minutoli L, Marini H, Abbritti RV, Squadrito F, Trichilo V, Valenti A et al (2016) ROS and brain gliomas: an overview of potential and innovative therapeutic strategies. Int $\mathrm{J}$ Mol Sci 17(6). https://doi.org/10.3390/ijms17060984

72. Wang M, Wang T, Liu S, Yoshida D, Teramoto A (2003) The expression of matrix metalloproteinase-2 and -9 in human gliomas of different pathological grades. Brain Tumor Pathol 20(2):65-72

73. Sciume G, Santoni A, Bernardini G (2010) Chemokines and glioma: invasion and more. J Neuroimmunol 224(1-2):8-12. https:// doi.org/10.1016/j.jneuroim.2010.05.019

74. See AL, Chong PK, Lu SY, Lim YP (2014) CXCL3 is a potential target for breast cancer metastasis. Curr Cancer Drug Targets 14(3): 294-309

75. Gui SL, Teng LC, Wang SQ, Liu S, Lin YL, Zhao XL, Liu L, Sui HY et al (2016) Overexpression of CXCL3 can enhance the oncogenic potential of prostate cancer. Int Urol Nephrol 48(5):701-709. https://doi.org/10.1007/s11255-016-1222-2

76. Dwyer J, Hebda JK, Le Guelte A, Galan-Moya EM, Smith SS, Azzi S, Bidere N, Gavard J (2012) Glioblastoma cell-secreted interleukin-8 induces brain endothelial cell permeability via CXCR2. PLoS One 7(9):e45562. https://doi.org/10.1371/journal.pone.0045562

77. Bradshaw A, Wickremsekera A, Tan ST, Peng L, Davis PF, Itinteang T (2016) Cancer stem cell hierarchy in glioblastoma multiforme. Front Surg 3:21. https://doi.org/10.3389/fsurg.2016. 00021

Publisher's Note Springer Nature remains neutral with regard to jurisdictional claims in published maps and institutional affiliations. 